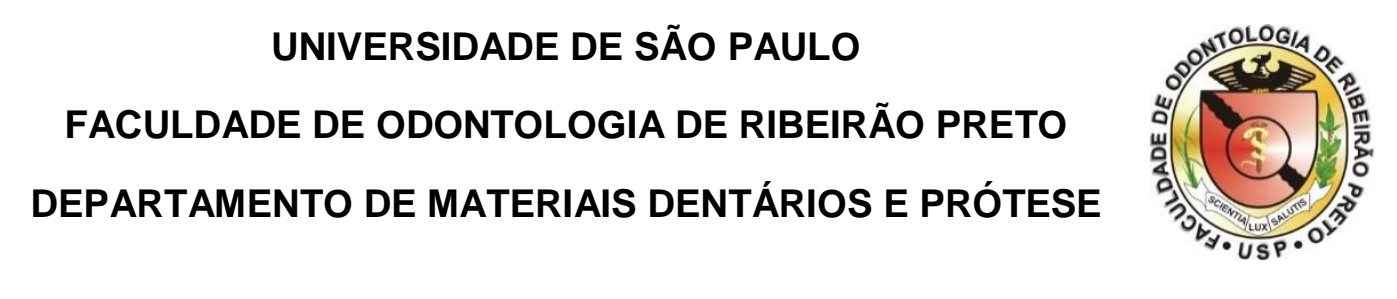

RAÍSA CASTELO BESSA NOGUEIRA

\title{
Molhabilidade da dentina erodida sob ação de dentifrícios dessensibilizantes
}

Ribeirão Preto 



\section{RAÍSA CASTELO BESSA NOGUEIRA}

Molhabilidade da dentina erodida sob ação de dentifrícios

dessensibilizantes

Dissertação apresentada à Faculdade de Odontologia de Ribeirão Preto da Universidade de São Paulo, junto ao Programa de Pós-graduação em Odontologia do Departamento de Materiais Dentários e Prótese, para a obtenção do título de Mestre em Ciências.

Área de concentração: Reabilitação Oral.

Orientadora: Profa. Dra. Alma Blásida Concepcion Elizaur Benitez Catirse

\section{Versão corrigida}

(Versão original encontra-se na unidade que aloja o Programa de Pós-graduação)

Ribeirão Preto 
Autorizo a reprodução e divulgação total ou parcial deste trabalho, por qualquer meio convencional ou eletrônico, para fins de estudo e pesquisa, desde que citada a fonte.

Ficha catalográfica elaborada pela Biblioteca Central do Campus USP - Ribeirão Preto

Nogueira, Raísa Castelo Bessa

Molhabilidade da dentina erodida sob ação de dentifrícios dessensibilizantes. Ribeirão Preto, 2016.

$88 p$ : 15il.; $30 \mathrm{~cm}$

Dissertação de Mestrado, apresentada à Faculdade de Odontologia de Ribeirão Preto da Universidade de São Paulo. Área de concentração: Reabilitação Oral.

Orientadora: Catirse, Alma Blásida Concepcion Elizaur

1. Molhabilidade. 2. Dentifrícios. 3. Hipersensibilidade da Dentina. 
Nome: Raísa Castelo Bessa Nogueira

Título: Molhabilidade da dentina erodida sob ação de dentifrícios dessensibilizantes.

Dissertação apresentada à Faculdade de Odontologia de Ribeirão Preto da Universidade de São Paulo, junto ao Programa de Pós-graduação em Odontologia do Departamento de Materiais Dentários e Prótese, para a obtenção do título de Mestre em Ciências.

Área de concentração: Reabilitação Oral.

Aprovado em:

BANCA EXAMINADORA

$\operatorname{Prof}(a) . \operatorname{Dr}(\mathrm{a}) .:$

Instituição:

Julgamento:

Assinatura:

Prof(a). Dr(a).:

Instituição:

Julgamento:

Assinatura:

Prof(a). $\operatorname{Dr}(a)$.:

Instituição:

Julgamento:

Assinatura: 

Dedicatánia 

ADeus, que sempre esteve comigo em tados as momentas com Seu amar incondicional.

A minha mãe Gailene Pastela Bessa de Oliveira que, mesmo com tedas as dificuldades, jamais desistiu de mim e é meu alicerce en tados as mamentos, sempre sanhanda junta comigo.

Ao meu naiva Tiaga Drumand Valadares Freitas pela compreensãa e suparte nos momentes difíceis e por compartithar as alegrias dessa jornada.

A minha familia, em especial ao meu irmão Rafael Pastelo Bessa Carapeba e meu avê Gaime Campela Dessa pela suparte e carinho. 



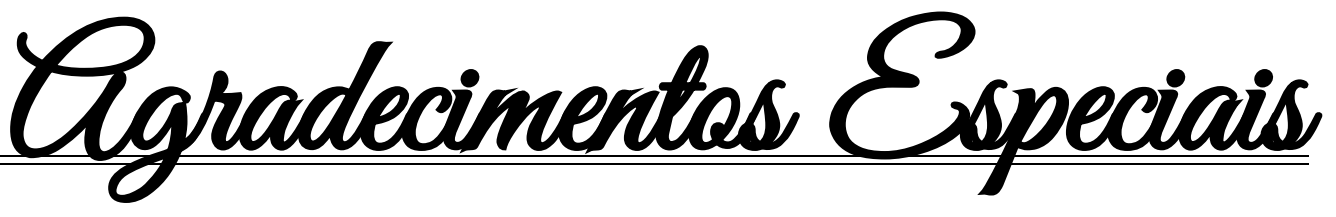



A minha orientadera Glma Blasida E. E. B. Catirse por ter me acelhide como orientada, me oferecida seu conhecimenta e disponibilidade e ter acheditado em mim para a excecuçãe deste trabalho.

A professara Silmara Clparecida OMilori Qarana e à professora Ana Paula Ramas, que contriburram com dedicação e conhecimento para a realização deste trabalho desde a inúcia. 



A Faculdade de Odontalagia de Ribeirãa Preto da Oniversidade de São Paula (FORP-USP), representada pela Senhora Diretara, Profa. Dra. Léa Assed Bezerra da Sibva, par ter me recebida como aluna de Mestrado.

A Paordenação do Programa de Pós-Graduação en Reabilitação Oral da Faculdade de Odontalogia de Ribeirãa Preto da Oniversidade de São Paulo, representada pela coardenadera Professara Dra. Rassana Pereira de Olmeida Antunes, pelo comprometimento em aprimerar o aprendizado e nossa formação na Pés- Graduação.

A OAPES (Caordenaçãa de Aperfeiçaamenta de Pessaal de Nüvel Superior), pela bolsa concedida.

Aros Professares da Departamenta de OMateriais Dentárias e Prátese da FORP/USP por compartitharem tado seu conhecimento em pral da nossa formação profissional.

A minha dupla de mestrado OMayara OManfrin Arnez, por dividir comiga todes as momentes dessa jornada. Sempre companheira e dedicada, parceira nos mementos de alegrias, preacupaçães, thistezas e comemaraçães.

Qlas meus amigas mais que especiais ONicale Gancabues Lima e Patrick Racha Osbarne pela amizade sincera e por representarem um "pedacinho de casa" e tornarem as dias de saudade de casa mais leves.

A Bruna Santas Ftonária Ganin, Brena Ftanária Ganin e seus pais, par me acalherem e me ajudarem sempre que necessário. 
Clos amigos que fiz durante este tempa, em especial à Caraline Barges, par tados ass mementas especiais que vivemos juntas.

Clos amigos e colegas de Pás-Graduaçãa pela cenvivência e por estarem sempre presentes nos mementes felizes e dificeis dessa etapa.

A todos que participaram de todas as formas possúveis para que este sonho se concretizasse.

\section{OMata abrigadal}


NOGUEIRA, RCB. Molhabilidade da dentina erodida sob ação de dentifrícios dessensibilizantes. 2016. 88p. Dissertação. Faculdade de Odontologia de Ribeirão Preto, Universidade de São Paulo.

\section{RESUMO}

Os dentifrícios dessensibilizantes que obliteram os túbulos dentinários atuam por meio do depósito de minerais na superfície e nos túbulos da dentina, o que pode provocar alteração nas propriedades de adesão da superfície dental, como a molhabilidade do substrato pelo adesivo. Assim, o objetivo do estudo foi avaliar o efeito do dentifrício dessensibilizante sobre a molhabilidade da dentina erodida e analisar a topografia da dentina tratada por meio da Microscopia Confocal a Laser antes e depois do condicionamento ácido. Oitenta fragmentos de dentina bovina $(7 \mathrm{~mm} \times 7 \mathrm{~mm})$, foram planificados, polidos e imersos em $10 \mathrm{~mL}$ de ácido cítrico $(\mathrm{pH}=3,2)$ durante 2 horas. Os espécimes foram divididos aleatoriamente de acordo com o dentifrício utilizado: dentifrício sem ação dessensibilizante (fluoreto de sódio) - controle $\left(D_{1}\right)$; arginina $8 \%$ e carbonato de cálcio - Colgate $\AA^{\circledR}$ Sensitive Pró-Alívio $\left(D_{2}\right)$; fosfosilicato de cálcio e

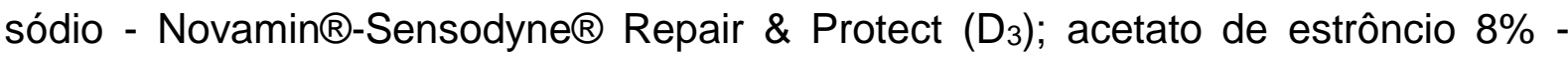
Sensodyne ${ }^{\circledR}$ Rápido Alívio $\left(D_{4}\right)$ e tempo de simulação de escovação de 7 dias $\left(T_{1}\right)$ e 21 dias $\left(T_{2}\right)$. Os corpos de prova foram submetidos a ciclos de escovação mecânica de 3 e 9 minutos, equivalente a 7 e 21 dias de escovação, 3 vezes ao dia, respectivamente, com escova macia. O condicionamento da dentina foi realizado com ácido fosfórico $37 \%$ por 15 segundos. Uma gota do sistema adesivo Single Bond Universal (3M) foi depositada na superfície de cada espécime e o ângulo de contato entre a superfície da dentina e o sistema adesivo foi medido utilizando um Goniômetro. Doze novos corpos de prova $(n=3)$ foram escovados nas mesmas condições experimentais por 21 dias e a topografia da dentina foi observada com Microscópio Confocal a Laser, antes e após o condicionamento ácido das superfícies escovadas. Os dados foram submetidos a Análise de Variância (ANOVA) a dois fatores $(p>0,05)$. Não houve diferença entre o ângulo de contato obtido na dentina erodida submetida à escovação com os dentifrícios dessensibilizantes. Os resultados demonstraram que o fator tempo foi estatisticamente significante $(p<0,05)$ sob a variável molhabilidade, enquanto o fator tratamento isoladamente bem como a sua interação com o tempo não tiveram efeito estatisticamente significante na variável do estudo $(p \geq .05)$. Portanto, conclui-se que uso de dentifrícios dessensibilizantes não interfere na molhabilidade da dentina erodida após 7 e 21 dias de escovação e o fator tempo de escovação, isoladamente, determinou redução da molhabilidade após 21 dias.

Palavras-chave: Molhabilidade, Dentifrícios, Hipersensibilidade da Dentina. 

NOGUEIRA, RCB. Eroded dentin wettability under effect of desensitizing dentifrices. 2016. 88p. Dissertation. Faculdade de Odontologia de Ribeirão Preto, Universidade de São Paulo.

\begin{abstract}
Desensitizing dentifrices that occlude dentinal tubules act by mineral deposition on the surface and inside dentinal tubules, which may cause may cause changes in the adhesion properties of the dental surface, such as the substrate wettability by adhesive systems. The aim of this study was to evaluate the effect of desensitizing dentifrices on the wettability and topographic analysis of eroded dentin. Eighty fragments of bovine dentin $(7 \mathrm{~mm} \times 7 \mathrm{~mm})$ were planned, polished and immersed in $10 \mathrm{~mL}$ of $0,3 \%$ citric acid $(\mathrm{pH}=3,2)$ during 2 hours. The specimens were randomly divided in eight groups according to the desensitizing agent: sodium fluoride - control (C); $8 \%$ arginine and calcium carbonate $\left(\mathrm{DA}_{1}\right)$; sodium calcium phosphosilicate $\left(\mathrm{DA}_{2}\right)$; and strontium acetate $\left(D A_{3}\right)$ and brushing time simulation ( 7 and 21 days). The specimens were submitted to mechanic brushing cycles of 3 and 9 minutes, equivalents to 7 and 21 days of brushing, three times a day, with a soft brush. Dentin etch with $37 \%$ phosphoric acid for 15 seconds and then washed for 30 seconds. A drop of $10 \mu \mathrm{L}$ adhesive system Single Bond Universal (3M ESPE) were placed on each specimen surface and the contact angle between dentin surface and adhesive system were measured using a Goniometer. Twelve other specimens $(n=3)$ were brushed under the same experimental conditions for 21 days and the dentin topography was observed with Confocal Laser Scanning Microscope, before and after etch of the brushed dentin surfaces. Data were summited to 2-way ANOVA analysis and the results presented that the time factor had a statistically significant effect $(p<0.05)$ on the wettability variable, while the treatment factor alone and the interaction between treatment and time factors, had no statistically significant effect on the variable study $(p \geq 0.05)$. Therefore, the use of desensitizing dentifrices did not interfere with the wettability of etched dentin after 7 and 21 days of brushing. Brushing time factor, alone, determined reduction of wettability after 21 days.
\end{abstract}

Keywords: Wettability, Dentifrices, Dentin hypersensitivity 



\section{LISTA DE FIGURAS}

Figura 1 - Secção transversal da junção amelocementária em incisivo bovino

Figura 2 - Fragmento de dentina de $7 \mathrm{~mm} \times 7 \mathrm{~mm}$ (corpo de prova)

Figura 3 - Acabamento e polimento dos corpos de prova em politriz.

Figura 4 - Materiais utilizados.

Figura 5 - Máquina de escovação do tipo Pepsodent. 50

Figura 6 - Fixação da escova na máquina de escovação. 50

Figura 7 - Condicionamento da dentina com ácido fosfórico 37\% por 15 segundos....51

Figura 8 - Goniômetro Optical Contact Angle Measurements - OCA20. .52

Figura 9 - Gota do adesivo sendo dispensada sobre o corpo de prova.

Figura 10 - gota de 10 $\mu \mathrm{L}$ do adesivo (Single Bond Universal) sobre o corpo de prova centralizado sobre a mesa.

Figura 11 - Imagem da gota processada em microcomputador com seu perfil e tangentes do ângulo formado com a superfície do lado esquerdo e do lado direito extraídos pelo software.

Figura 12 - Representação esquemática do ângulo de contato formado entre o substrato e uma gota do adesivo, nas diferentes condições experimentais.

Figura 13 - (A) Fotomicrografia da dentina escovada com dentifrício controle (D1) antes do condicionamento com ácido fosfórico 37\%. (B) Fotomicrografia do mesmo corpo de prova após o condicionamento ácido da dentina por 15 segundos.

Figura 14 - (A) Fotomicrografia da dentina escovada com dentifrício contendo arginina $8 \%$ + carbonato de cálcio (D2) antes do condicionamento com ácido fosfórico $37 \%$. (B) Fotomicrografia do mesmo corpo de prova após o condicionamento ácido da dentina por 15 segundos.

Figura 15 - (A) Fotomicrografia da dentina escovada com dentifrício contendo fosfosilicato de cálcio e sódio (D3) previamente ao condicionamento ácido; (B) D3 após condicionamento ácido; (C) Fotomicrografia da dentina escovada com dentifrício contendo acetato de estrôncio 8\% (D4) previamente ao condicionamento ácido; (D) D4 após condicionamento ácido. 



\section{LISTA DE TABELAS}

Tabela 1 - Resumo da análise de variância. .58

Tabela 2 - Médias de ângulo de contato $(\theta)$ do fator Dentifrício. .58

Tabela 3 - Médias de ângulo de contato $(\theta)$ do fator Tempo de Escovação .59

Tabela 4 - Médias de ângulo de contato $(\theta)$ da interação Dentifrício x Tempo de Escovação. 60 



\section{LISTA DE GRÁFICOS}

Gráfico 1 - Médias de ângulo de contato $(\theta)$ do fator Dentifrício............................................59

Gráfico 2 - Médias de ângulo de contato $(\theta)$ do fator Tempo de Escovação............................59

Gráfico 3 - Médias de ângulo de contato $(\theta)$ da interação Dentifrício x Tempo de Escovação..60 



\section{SUMÁRIO}

\section{RESUMO}

\section{ABSTRACT}

\section{LISTA DE FIGURAS}

\section{LISTA DE TABELAS}

\section{LISTA DE GRÁFICOS}

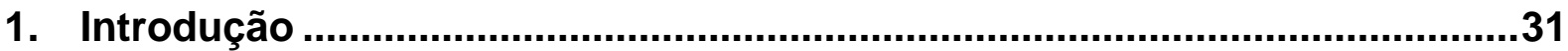

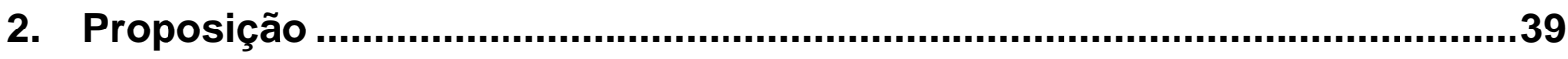

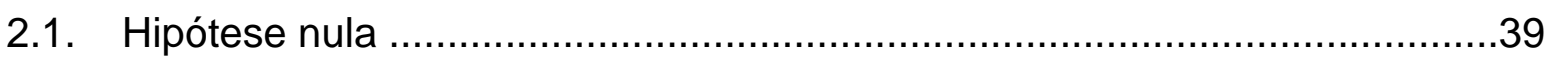

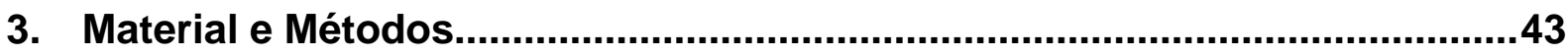

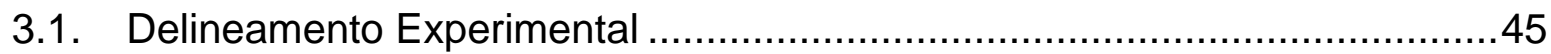

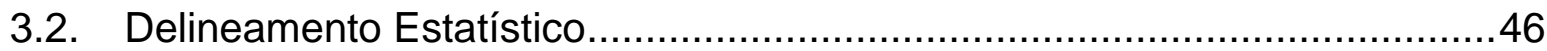

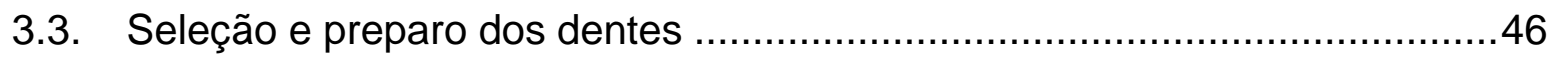

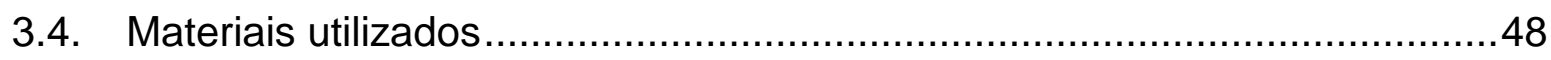

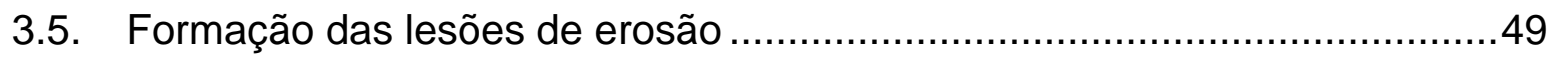

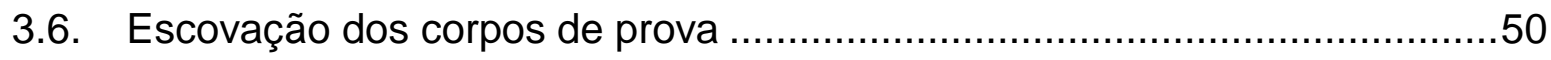

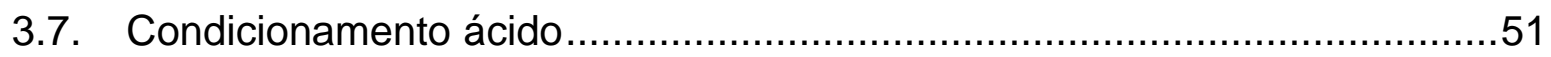

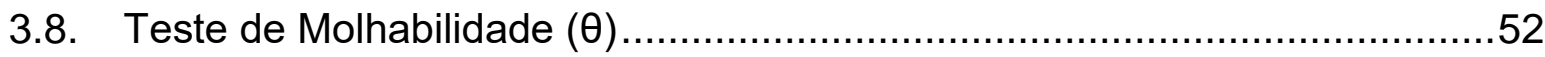

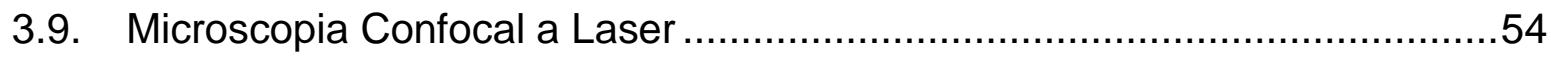

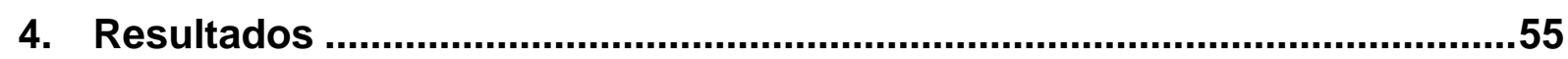

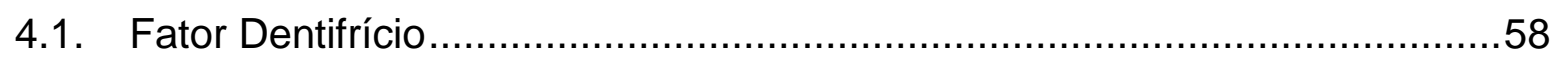

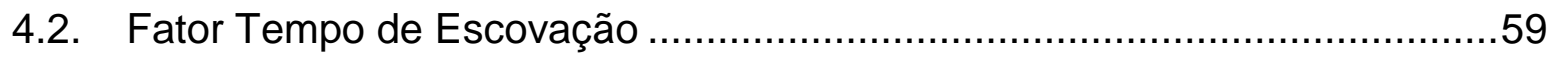

4.3. Interação entre fatores Dentifrício $x$ Tempo de Escovação ..........................60

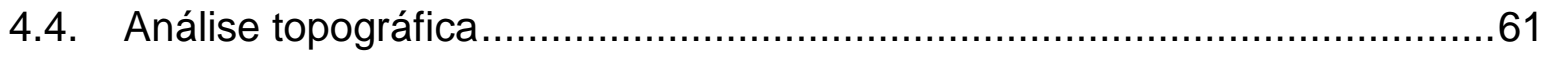

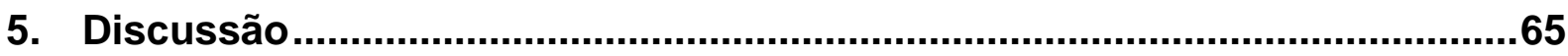

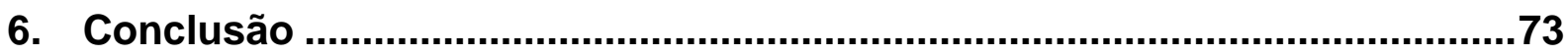

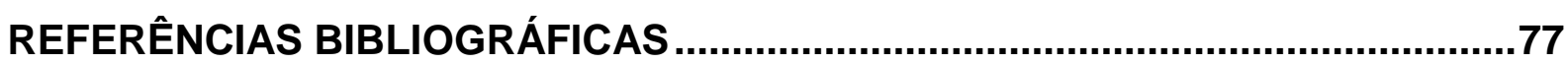

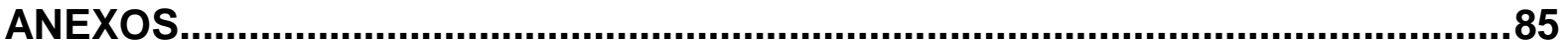



Ontraduçãa 



\section{Introdução}

A hipersensibilidade dentinária é definida como uma dor dental aguda proveniente da dentina exposta em resposta a diferentes estímulos, tais como os estímulos térmico, evaporativo, tátil, osmótico ou químico, a qual não pode ser associada a nenhuma patologia ou defeito dentário, descartado através de um adequado diagnóstico diferencial (Addy, 2002; Cummins, 2009). Clinicamente, consiste em uma dor breve, aguda e de início rápido, podendo ser localizada ou generalizada, afetando uma ou mais superfícies simultaneamente (Mantzourani, Sharma, 2013; Pinto et al., 2014).

A prevalência da hipersensibilidade dentinária encontrada em diversos estudos (Chabanski et al., 1997; Gillam et al., 2002; Mantzourani, Sharma, 2013; Naidu et al., 2014; Costa et al., 2014; Haneet, Vandana, 2016) abrange cerca de $30 \%$ da população, mas pode chegar a até $98 \%$ em pacientes com doenças periodontais (Mantzourani, Sharma, 2013).

Os principais fatores etiológicos da hipersensibilidade dentinária são a recessão gengival e a perda de esmalte, os quais levam à exposição da superfície dentinária (Cummins, 2009). A escovação dentária com força excessiva e tratamentos periodontais cirúrgicos ou não-cirúrgicos são fatores que predispõem o dente a recessão gengival, enquanto a perda de esmalte pode estar relacionada com atrições, erosões ou abrasões, além da ocorrência de traumas oclusais ( Cummins, 2009; Bal et al., 2015). Estes fatores possuem íntima relação com a exposição dos túbulos dentinários, permeabilidade da dentina e a hipersensibilidade dentinária (Pinto et al., 2014).

A Teoria Hidrodinâmica, proposta por Brännström em 1986, é a explicação mais aceita para o mecanismo de resposta sensorial da dentina. Consiste na transmissão de diferentes estímulos (térmicos, táteis, osmóticos, evaporativos e/ou químicos) aplicados à dentina aos nervos da polpa pela movimentação dos fluidos no interior dos túbulos dentinários, gerando a sensação dolorosa (Brännström, 1986). O fluxo dos fluidos dentinários aumentado provoca uma mudança de pressão através da 
dentina, que ativa nervos intradentais localizados na região pulpar da dentina dentro dos túbulos dentinários, provavelmente devido à resposta de mecanorreceptores que ativam os nervos pulpares. Além disso, a movimentação dos fluidos provoca uma descarga elétrica diretamente proporcional à pressão, chamada de "potencial de fluxo" (Addy, 2002).

Existem diversas formas de tratamento para a hipersensibilidade dentinária, como o uso de agentes dessensibilizantes em géis, dentifrícios e enxaguatórios bucais aplicados sobre a dentina exposta em consultório ou de uso caseiro, e a possibilidade de aplicar vernizes, realizar restaurações com resinas compostas, cimento de ionômero de vidro, adesivos dentinários e lasers de baixa potência (Markowitz, Pashley, 2007).

O tratamento mais utilizado para a hipersensibilidade dentinária é por meio de dentifrícios de uso diário que possuem substâncias dessensibilizantes que atuarão na obliteração dos túbulos dentinários ou no bloqueio da transmissão do estímulo doloroso (Cummins, 2009; Davies et al., 2011; Pinto et al., 2014; Jones et al., 2015). Os agentes dessensibilizantes podem ser aplicados pelo cirurgião-dentista em consultório, proporcionando alívio mais imediato, ou na forma de dentifrícios de uso diário, recomendados de acordo com a necessidade do paciente. Os agentes presentes nos dentifrícios que atuam na obliteração dos túbulos dentinários são a arginina 8\% associada ao carbonato de cálcio, o acetato de estrôncio 8\%, 0 fosfosilicato de cálcio e sódio, a hidroxiapatita, dentre outros. Estas substâncias atuam ligando-se aos componentes da dentina formando tampões que obliteram o túbulo dentinário (Davies et al., 2011; Pinto et al., 2014; Jones et al., 2015).

O estrôncio foi um dos primeiros agentes dessensibilizantes a ser pesquisado, com estudos desde a década de 50 (Cohen, 1961). Inicialmente, foi estudado na forma de cloreto de estrôncio, porém, esta composição não era considerada muito eficiente no tratamento da hipersensibilidade (Mantzourani, Sharma, 2013). O estrôncio está presente naturalmente no esmalte e na dentina e, devido à sua capacidade de atuar de forma semelhante ao cálcio, substituindo-o na formação de hidroxiapatita (cálcio estrôncio apatita - $\left.\mathrm{Ca}_{6} \mathrm{Sr}_{4}\left(\mathrm{PO}_{4}\right)_{6}(\mathrm{OH})_{2}\right)$, pode-se dizer que possui atividade remineralizadora (Parkinson, Wilson, 2011). O acetato de estrôncio surgiu, em substituição ao cloreto de estrôncio, por ser compatível com os íons fluoreto presente 
nos dentifrícios de uso diário, mantendo sua eficácia na deposição de estrôncio e obliteração dos túbulos dentinários (Davies et al., 2011; Olley et al., 2012; Orsini et al., 2013; Saeki et al., 2016).

Saeki et al. (2016) avaliaram os efeitos da utilização de dentifrícios contendo acetato de estrôncio na obliteração dos túbulos dentinários e nas propriedades micromecânicas de dentina radicular sadia e em dentina desmineralizada. Constataram que a escovação dental com essa substancia obliterou de forma efetiva os túbulos dentinários em ambas condições experimentais e aumentou o módulo de elasticidade da dentina desmineralizada. Os autores relacionaram a alteração na propriedade mecânica com a semelhança que o estrôncio tem com o cálcio, podendo formar sais de fosfato de estrôncio, tendo ação química direta sobre a dentina pela formação de estrôncio-apatita.

Recentemente, incluíram-se vidros bioativos e biocompatíveis nos produtos para o tratamento da hipersensibilidade pela obstrução dos túbulos dentinários. 0 fosfosilicato de cálcio e sódio (Novamin®) é um vidro bioativo capaz de obliterar os túbulos dentinários pela precipitação de minerais insolúveis através da formação de novos cristais de carbonato de cálcio na superfície dental. Ao ser exposto a ambiente aquoso, como a saliva, há uma rápida a liberação de íons sódio e dissolução de íons cálcio, fosfato e de sílica na superfície do vidro, resultando na formação de um gel policondensado rico em sílica sobre a superfície dentinária. Sob este gel são formados sítios de nucleação para a precipitação de fosfato de cálcio, o qual cristalizase em hidroxicarbonatoapatita. A deposição mineral do Novamin® inicialmente ocorre na forma de partículas individuais e, com o tempo, sua degradação promove uma superfície mais homogênea sobre a dentina, também sendo capaz de penetrar nos túbulos dentinários (Gjorgievska et al., 2013; Mantzourani, Sharma, 2013; Bae et al., 2015; Jones et al., 2015).

Jones et al. (2015) investigou a capacidade de dentifrício com fosfosilicato de cálcio e sódio em remineralizar a dentina e ocluir os túbulos dentinários. Os autores perceberam que a utilização dessa substância, com o tempo, aumenta a microdureza da dentina e é capaz de obliterar os túbulos dentinários.

No estudo de Satyapal et al. (2014) comparou-se a eficácia do dentifrício contendo $5 \%$ de fosfosilicato de cálcio e sódio com dentifrícios cujo princípio ativo era 
o nitrato de potássio, conhecido por sua atividade de bloquear a resposta neural da dor causada pela hipersensibilidade e não obliterar os túbulos dentinários. Os autores observaram que o fosfosilicato de cálcio e sódio mostrou maior capacidade em reduzir os sintomas da hipersensibilidade dentinária quando comparado ao nitrato de potássio, além de apresentar eficácia prolongada após a suspensão do uso do dentifrício.

A arginina $8 \%$ associada ao carbonato de cálcio nos dentifrícios surgiu sob a premissa de que o tratamento da hipersensibilidade dentinária ideal deve mimetizar o processo de dessensibilização natural pela saliva, a qual transporta cálcio e fosfato para o interior dos túbulos além de formar uma camada de glicoproteínas sobre a superfície dental que contém cálcio e fosfato, em pH alcalino. Esse mecanismo natural não é rápido o suficiente para promover a obliteração dos túbulos, portanto, foi elaborado um dentifrício que mimetiza esse mecanismo composto por arginina, carbonato de cálcio e fluoreto na forma de monofluorofosfato de sódio (1450ppm). A arginina é um aminoácido carregado positivamente em pH fisiológico e o carbonato de cálcio age como provedor de cálcio. Os dentifrícios que contém arginina $8 \%+$ carbonato de cálcio promovem uma redução da quantidade de carbono e nitrogênio presentes na dentina e aumentam significativamente a concentração de cálcio, oxigênio e fósforo. Assim, promove a remineralização da superfície dentinária e obliteração dos túbulos com um tampão de composição mineral semelhante à da própria dentina (Cummins, 2009).

Petrou et al. (2009) realizou um estudo para investigar a capacidade da arginina 8\% associada ao carbonato de cálcio em dentifrício e pasta profilática na obliteração dos túbulos dentinários e avaliaram a composição química dos depósitos sobre a superfície e no interior dos túbulos dentinários. Foi observado que tanto os dentifrícios de uso caseiro como a pasta profilática para uso em consultório obliteraram a maioria dos túbulos dentinários. Os tampões no interior dos túbulos e os depósitos minerais sobre a superfície da dentina apresentaram uma alta concentração de cálcio, fosfato e carbonato em sua composição e constataram que a arginina é incorporada ao tampão formado no túbulo dentinário. Por meio do teste de condução hidráulica, os autores observaram que a obliteração dos túbulos reduz o fluxo do fluido dentinário e é resistente tanto à pressão pulpar como a desafios ácidos externos. 
Diversos outros estudos comprovam a efetividade desses agentes dessensibilizantes na obliteração dos túbulos dentinários para o tratamento da hipersensibilidade dentinária (Davies et al., 2011; Eliades et al., 2013; West et al., 2013; Arnold et al., 2015; Bae et al., 2015; Bal et al., 2015; Chen et al., 2015; Jones et al., 2015; Olley et al., 2015; West et al., 2015; Zhu et al., 2015; Saeki et al., 2016), porém, há a necessidade de considerar o efeito da camada protetora formada pelos dentifrícios dessensibilizantes na adesão dos materiais restauradores ao substrato dental. Assim, pesquisas envolvendo esses agentes dessensibilizantes têm sido realizadas para verificar a resistência de união entre os agentes adesivos e a dentina em períodos curtos de aplicação (Wang et al., 2012; Yang, Pei, Chen, \& Lei, 2014; Pilo, Harel, Nissan, \& Levartovsky, 2016), porém, pesquisas relacionadas à interferência destes dentifrícios no espalhamento do adesivo dentinário no substrato dental precisam ser realizadas, visto que a molhabilidade da dentina é fundamental para o estabelecimento da adesão (Farge, Alderete, \& Ramos, 2010).

Para uma adesão eficiente, o íntimo contato entre o material adesivo e o substrato dentinário é necessário (Miyazaki et al., 2014; Saikaew et al., 2016). Portanto, para se obter a máxima área de contato entre um adesivo líquido e uma superfície sólida, o substrato deve apresentar uma boa molhabilidade em relação a este líquido, ou seja, o adesivo deverá espalhar-se espontaneamente sobre o substrato (Aguilar-Mendoza et al., 2008a; Farge et al., 2010). A molhabilidade é quantificado pela determinação do ângulo de contato formado entre o líquido e a superfície do substrato. Quanto menor o ângulo de contato, maior será a afinidade entre o adesivo e a dentina, o que representa maior molhabilidade da superfície dentinária, podendo aumentar a eficiência da adesão (Rosales-Leal et al., 2001; Farge et al., 2010). A molhabilidade de um determinado material está relacionada principalmente com sua composição química e topografia superficial (de Souza et al., 2014).

Previamente à aplicação do sistema adesivo, pode ser realizado o condicionamento do substrato dentinário com ácido fosfórico a 37\%, o qual promove uma desmineralização da dentina e remoção da smear layer em profundidade aproximada de 0,5 a $7,5 \mu \mathrm{m}^{2}$ (Pashley et al., 1993). Este preparo torna o substrato mais hidrofílico, aumentando a sua molhabilidade (Eick et al., 1997; Tsujimoto et al., 2016). 
Os dentifrícios dessensibilizantes depositam minerais, como o cálcio e o silício, sobre a superfície dental e no interior dos túbulos dentinários, o que pode alterar sua morfologia e composição (Gjorgievska et al., 2013). Além disso, a dentina é um substrato com alta energia de superfície, perfeitamente capaz de ser molhada por sólidos macios com baixo ponto de fusão ou líquidos, que possuem baixa energia de superfície, como o colágeno, os fluidos orais e os adesivos. Devido a esta afinidade, o substrato dental com alta energia de superfície pode ser facilmente contaminado pelos líquidos (Marshall et al., 2010). Sendo assim, em decorrência dessas alterações superficiais, a utilização desses dentifrícios pode interferir na molhabilidade do substrato, alterando o espalhamento do adesivo (Eliades et al., 2013; Wang et al., 2015).

O tratamento da hipersensibilidade dentinária com os dentifrícios dessensibilizantes deve ser indicado pelo cirurgião-dentista após o correto diagnóstico. Estes dentifrícios são de fácil acesso, vendidos em farmácias e supermercados, possuem custo reduzido quando comparados a procedimentos realizados em consultório, além de eficientes, como comprovam os estudos de Bae et al. (2015) e Orsini et al. (2013). A eficiência dos dentifrícios com agentes dessensibilizantes no tratamento da hipersensibilidade dentinária, bem como a aplicação caseira, a propaganda em massa nas principais mídias e o acesso facilitado leva à ampla utilização destes produtos pelos pacientes, mesmo que sem indicação profissional.

Após o tratamento contínuo com os dessensibilizantes o paciente pode ainda necessitar de procedimentos restauradores, como a restauração de lesões não cariosas (abfração) ou recobrimento radicular. Então, a necessidade de novos estudos que comprovem sua eficiência sem interferir no comportamento clínico do material restaurador é importante. 
Phopesiçãa 



\section{Proposição}

O objetivo deste estudo foi analisar a molhabilidade da dentina erodida submetida à ação de dentifrícios com diferentes agentes dessensibilizantes nos períodos de 7 e 21 dias de escovação e realizar uma análise complementar da topografia da dentina escovada antes e após o condicionamento ácido.

\subsection{Hipótese nula}

Não haverá diferença na molhabilidade da dentina erodida quando:

a) submetida aos diferentes dentifrícios dessensibilizantes;

b) submetida à ação de dentifrícios dessensibilizantes nos períodos de 7 e 21 dias de escovação. 

OMaterial e OMetadas 



\section{Material e Métodos}

\subsection{Delineamento Experimental}

Para o estudo da variável molhabilidade da dentina erodida em função dos diferentes tipos de dentifrícios dessensibilizantes foi realizado o teste piloto para estabelecer os fatores de variação, ajustar a metodologia e controlar aqueles fatores que não interessavam ao estudo.

Os fatores de estudo determinados com as suas siglas foram:

a. Dentifrício (D), com 4 níveis:

$\mathbf{D}_{1}$ - dentifrício convencional (grupo controle);

D2 - dentifrício à base de arginina 8\% e carbonato de cálcio;

$D_{3}$ - dentifrício à base de fosfosilicato de cálcio e sódio;

$D_{4}$ - dentifrício à base de acetato de estrôncio.

b. Tempo de Escovação (T), com 2 níveis:

$\mathbf{T}_{1}$ - 3 min de escovação equivalente a 7 dias;

$\mathbf{T}_{2}$ - 9 min de escovação equivalente a 21 dias.

Análise topográfica complementar em Microscópio Confocal a Laser após o tratamento e após o condicionamento ácido da dentina no tempo de 21 dias de escovação. 


\subsection{Delineamento Estatístico}

A amostra do experimento foi composta por 92 incisivos bovinos dos quais foram preparados 80 corpos de prova $(n=10)$ para análise da molhabilidade, divididos aleatoriamente em 8 grupos, e 12 corpos de prova $(n=3)$ para análise topográfica complementar dos dentes submetidos às diferentes condições experimentais propostas, antes e após o condicionamento ácido da dentina, por meio do Microscópio Confocal a Laser.

O modelo fatorial foi $4 \times 2$.

Assim, para a molhabilidade foram realizadas o total de 160 medições, sendo duas leituras por corpo de prova, totalizando 80 leituras. Os dados obtidos foram agrupados em tabelas e submetidos ao teste estatísticos de Normalidade, ShapiroWilk e Anova por meio do Programa Estatístico Assistat versão 7.7 beta - 2016 .

\subsection{Seleção e preparo da amostra}

Incisivos bovinos armazenados em solução de timol $0,01 \%$ a 9 $\mathrm{C}$ foram lavados em água corrente por 24 horas para eliminar os resíduos de timol, sendo selecionados 92 dentes hígidos, excluindo dentes com trincas ou defeitos dentários e de tamanho muito reduzido (Soares et al., 2016). Os dentes foram seccionados transversalmente na junção amelocementária para separar as coroas das raízes (Figura 1), por meio de disco diamantado (série 15HC 11-4244, Buehler, Illinois, EUA), montado em máquina de corte Minitom (Struers A/S, Ballerup, Dinamarca - Departamento de Odontologia Restauradora da FORP/USP). Posteriormente, as coroas dentais foram seccionadas de modo a obter fragmentos de $7 \mathrm{~mm}$ de largura por $7 \mathrm{~mm}$ de comprimento de dentina (Figura 2). 


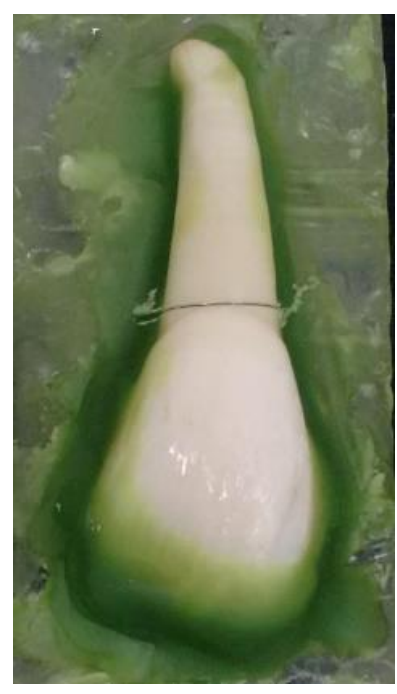

Figura 1 - Secção transversal na junção amelocementária em incisivo bovino.

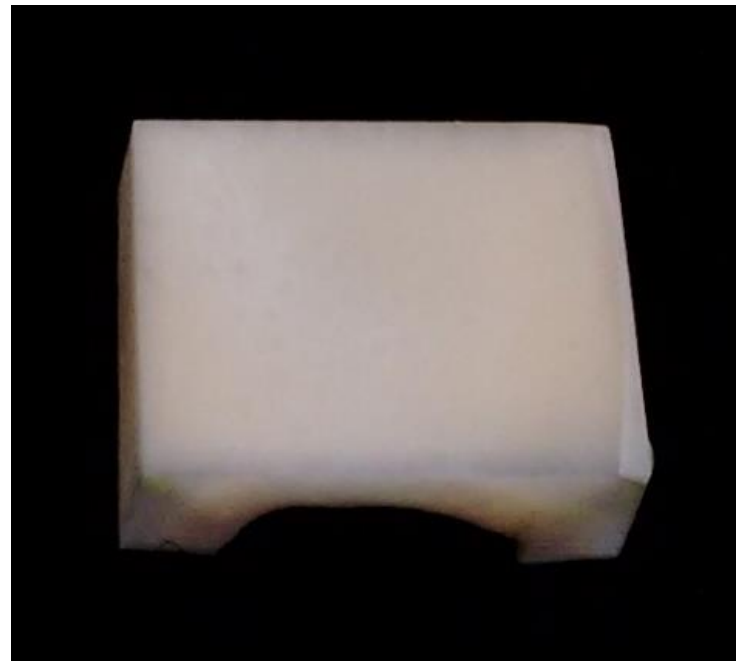

Figura 2 - Fragmento de dentina de $7 \mathrm{~mm}$ x $7 \mathrm{~mm}$ (corpo de prova).

Os fragmentos foram fixados em matriz de teflon utilizando-se cera fundida (Kota Industria e comercio Ltda, SP, Brasil) para planificar as superfícies de dentina, por meio da politriz Arotec APL-4 (Arotec S/AInd. Com, SP, Brasil) refrigerada à água com lixas d'agua com granulação de \#320 a \#600 para remover excessos laterais, além de obter o tamanho dos fragmentos, e para acabamento e planificação da superfície e formação da smear layer em cada corpo de prova foram utilizadas lixas de granulação \#1200 e \#2000 (Hermes Abrasives Ltd., VA, EUA) por 10 segundos (Figura 3).

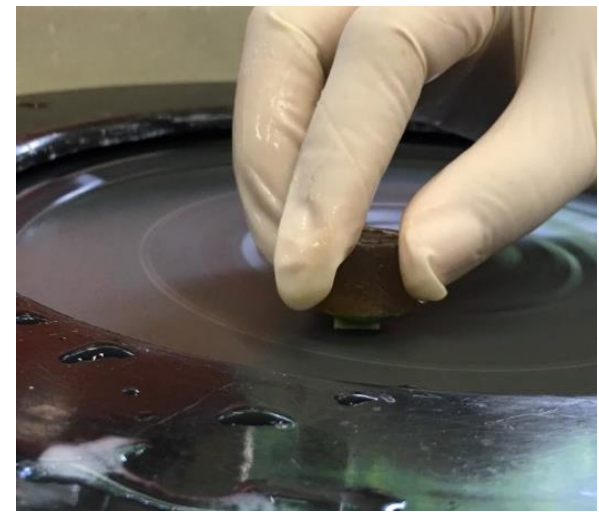

Figura 3 - Acabamento e polimento dos corpos de prova em politriz. 


\subsection{Materiais utilizados}

Os materiais utilizados no estudo estão descritos no Quadro 1 e na Figura 4.

Quadro 1 - Materiais utilizados com respectiva composição, lote, fabricante e local de fabricação.

\begin{tabular}{|c|c|c|c|c|}
\hline Material & Composição & Lote & Fabricante & Local \\
\hline $\begin{array}{l}\text { Ácido fosfórico } \\
37 \%\end{array}$ & Ácido fosfórico 37\% & 90615 & \begin{tabular}{|l|} 
FGM \\
Dentscare \\
LTDA \\
\end{tabular} & Joinville/SC \\
\hline $\begin{array}{l}\text { Dentifrício } \\
\text { Colgate Total } 12\end{array}$ & $\begin{array}{l}\text { Ingredientes ativos: Fluoreto } \\
\text { de sódio } 0,32 \%(1450 \mathrm{ppm} \text { de } \\
\text { flúor), triclosan } 0,3 \% \text {. }\end{array}$ & 4129BR123D & $\begin{array}{l}\text { Colgate- } \\
\text { Palmolive } \\
\text { Industrial } \\
\text { LTDA }\end{array}$ & $\begin{array}{l}\text { São Bernardo do } \\
\text { Campo/SP }\end{array}$ \\
\hline $\begin{array}{l}\text { Dentifrício } \\
\text { Colgate Sensitive } \\
\text { Pró-Alívio }{ }^{\mathrm{TM}}\end{array}$ & $\begin{array}{l}\text { Ingredientes ativos: arginina } \\
8 \% \text {, monofluoro-fosfato de } \\
\text { sódio } 1,1 \% \text { (1450ppm de } \\
\text { flúor). }\end{array}$ & 5290BR122C & $\begin{array}{l}\text { Colgate- } \\
\text { Palmolive } \\
\text { Industrial } \\
\text { LTDA }\end{array}$ & $\begin{array}{l}\text { São Bernardo do } \\
\text { Campo/SP }\end{array}$ \\
\hline $\begin{array}{l}\text { Dentifrício } \\
\text { Sensodyne } \\
\text { Rápido Alívio }\end{array}$ & $\begin{array}{l}\text { Ingredientes ativos: fluoreto } \\
\text { de sódio (1040ppm de flúor), } \\
\text { acetato de estrôncio. }\end{array}$ & UP0308V & $\begin{array}{ll}\text { GlaxoSmith- } \\
\text { Kline } & \text { Brasil } \\
\text { LTDA } & \end{array}$ & Rio de Janeiro/RJ \\
\hline $\begin{array}{l}\text { Dentifrício } \\
\text { Sensodyne } \\
\text { Repair \& Protect }\end{array}$ & \begin{tabular}{llr|} 
Ingredientes & ativos: \\
monofluorofosfato de sódio \\
(1426ppm de flúor), \\
fosfossilicato de cálcio e \\
sódio $5 \%$.
\end{tabular} & $295 \mathrm{~F}$ & $\begin{array}{l}\text { SmithKline } \\
\text { Beecham } \\
\text { Consumer } \\
\text { Healthcare }\end{array}$ & $\begin{array}{l}\text { Maidenhead - } \\
\text { Berkshire / Reino } \\
\text { Unido }\end{array}$ \\
\hline $\begin{array}{l}\text { Adesivo } \\
\text { SingleBond } \\
\text { Universal }\end{array}$ & 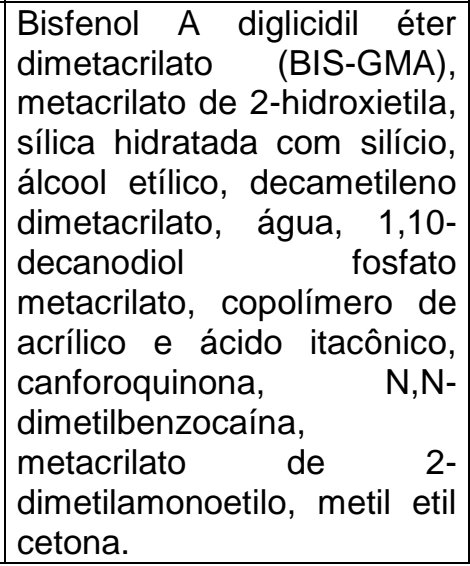 & 1502800252 & $\begin{array}{l}\text { 3M ESPE / } \\
\text { 3M do Brasil } \\
\text { LTDA }\end{array}$ & Sumaré/SP \\
\hline
\end{tabular}


A.

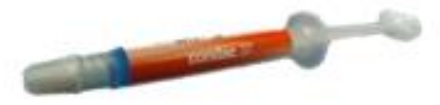

c.

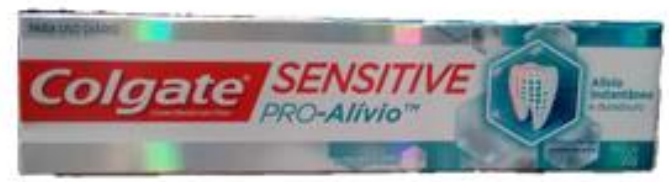

E.

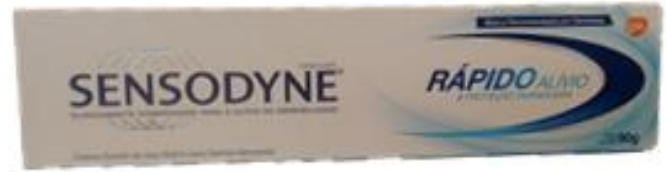

B.

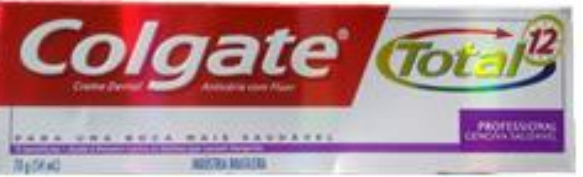

D.

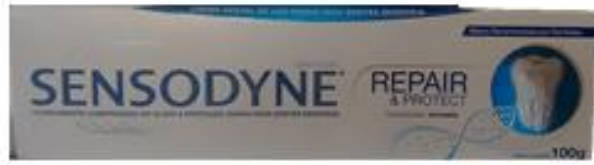

F.

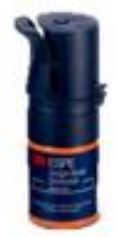

Figura 4 - (A) Ácido fosfórico 37\% Condac 37®; (B) dentifrício Colgate® Total 12; (C) dentifrício Colgate ${ }^{\circledR}$ Sensitive Pró-Alívio ${ }^{\mathrm{TM}}$; (D) dentifrício Sensodyne ${ }^{\circledR}$ Repair \& Protect; (E) dentifrício Sensodyne® Rápido Alívio; (F) Adesivo SingleBond Universal 3M ESPE.

\subsection{Formação das lesões de erosão}

Para induzir a formação das lesões de erosão (Vanuspong et al., 2002), cada corpo de prova foi imerso individualmente em $20 \mathrm{~mL}$ de ácido cítrico 0,3\% $(\mathrm{pH} 3,2)$ a temperatura ambiente e levados à máquina de agitação (CT155, Cientec, Piracicaba, SP, Brasil - Departamento de Odontologia Restauradora da FORP/USP) por 2 horas, com velocidade de $50 \mathrm{rpm}$. Após este desafio ácido inicial, os corpos de prova foram lavados por 10 segundos com água destilada e armazenados em $5 \mathrm{~mL}$ de saliva artificial por 24 horas à $37{ }^{\circ} \mathrm{C}$ (Scatolin et al., 2012). A saliva artificial foi composta de metilparabeno (2,0), carboximetilcelulose de sódio (10,0g), $\mathrm{KCl}(0,625 \mathrm{~g}), \mathrm{MgCl} 2.6 \mathrm{H}_{2} \mathrm{O}$ $(0,059 \mathrm{~g}) \mathrm{CaCl}_{2}-2 \mathrm{H}_{2} \mathrm{O}(0,166 \mathrm{~g}), \mathrm{K}_{2} \mathrm{HPO}_{4}(0,804 \mathrm{~g}), \mathrm{KH}_{2} \mathrm{PO}_{4}(0,326 \mathrm{~g})$ em $1000 \mathrm{~mL}$ de água destilada (Amaechi et al., 1999). 


\subsection{Escovação dos corpos de prova}

A escovação dos corpos de prova foi realizada em máquina de escovação do tipo Pepsodent (MAVTEC - Com. Peças, Acess. e Serv. Ltda. ME, Ribeirão Preto, São Paulo, Brasil - Departamento de Materiais Dentários e Prótese da FORP/USP), a qual permite a escovação de 12 espécimes simultaneamente (Figura 5) com velocidade de 356 rotações por minuto e curso percorrido pela escova correspondente a 3,8 centímetros (Sorgini et al., 2012). Foram utilizadas escovas dentais macias, sendo uma para cada dois corpos de prova. Os cabos das escovas foram cortados para serem encaixadas e fixadas por meio de parafusos situados nas laterais e na parte superior do suporte da máquina (Figura 6). Uma matriz foi confeccionada em resina acrílica autopolimerizável para acomodar os corpos de prova em posição padrão, fixados com cera n.7.

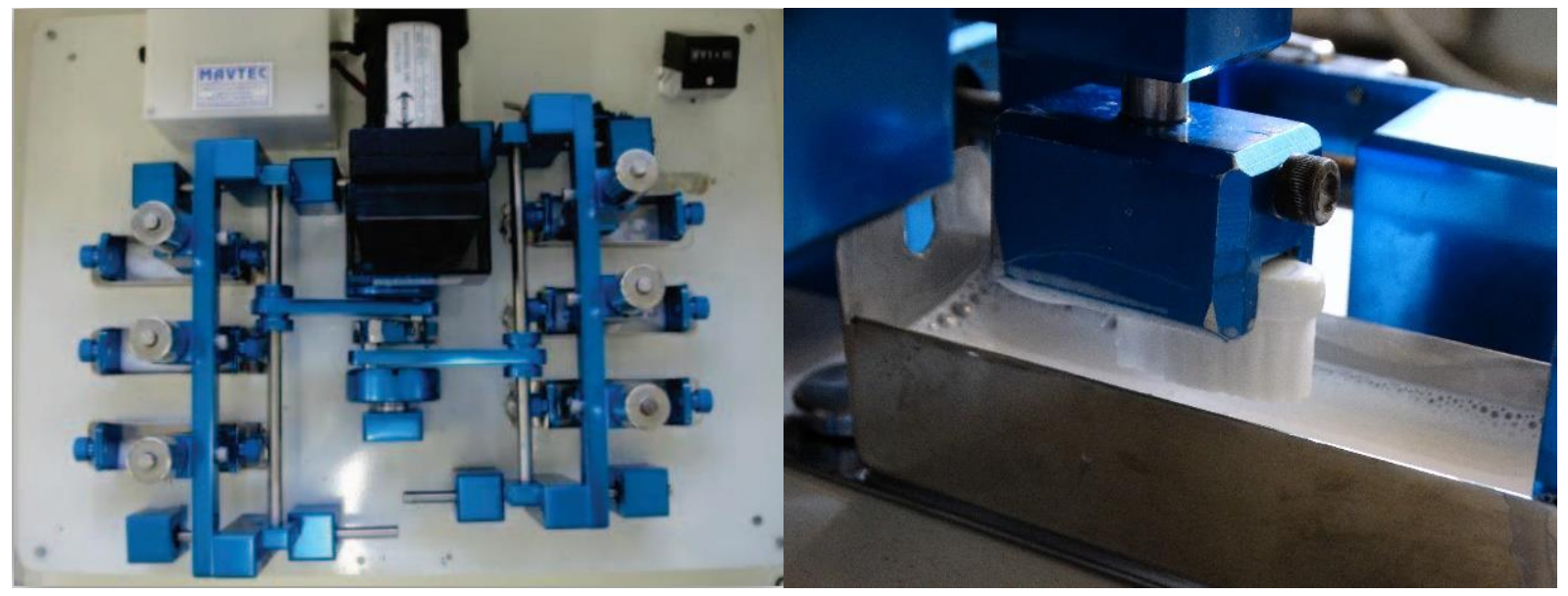

Figura 5 - Máquina de escovação do tipo Pepsodent.
Figura 6 - Fixação da escova na máquina de escovação.

Um volume de $10 \mathrm{~g}$ de cada dentifrício foi suspenso em $10 \mathrm{~mL}$ de água destilada (proporção 1:1) e vertido nas cubas do aparelho sobre os corpos de prova, de cada um dos grupos estabelecidos, sendo: dentifrício sem ação dessensibilizante (fluoreto 
de sódio) - controle $\left(D_{1}\right)$; arginina $8 \%$ e carbonato de cálcio - Colgate $\circledast$ Sensitive PróAlívio $^{\mathrm{TM}}\left(\mathrm{D}_{2}\right)$; fosfosilicato de cálcio e sódio - Novamin - Sensodyne $\AA^{\circledR}$ Repair \& Protect $\left(D_{3}\right)$; acetato de estrôncio 8\% - Sensodyne® Rápido Alívio $\left(D_{4}\right)$.

Os tempos de escovação foram de 3 minutos, correspondente a 1025 ciclos da máquina para simulação de 7 dias de escovação, três vezes ao dia $\left(T_{1}\right)$, e 9 minutos (3075 ciclos) para simular escovação pelo paciente, três vezes ao dia, durante 21 dias ( $\left.T_{2}\right)$ (Sorgini et al., 2012). Os corpos de prova foram lavados em água corrente durante 30 segundos, após a escovação e imersos novamente na saliva artificial em temperatura controlada.

\subsection{Condicionamento ácido}

Após 24 horas, todos os corpos de prova foram condicionados com ácido fosfórico 37\% (Condac 37®, FGM, Santa Catarina, Brasil) por 15 segundos (Figura 7), lavados com água por 30 segundos e levemente secos com papel absorvente, para posterior realização do teste de molhabilidade.

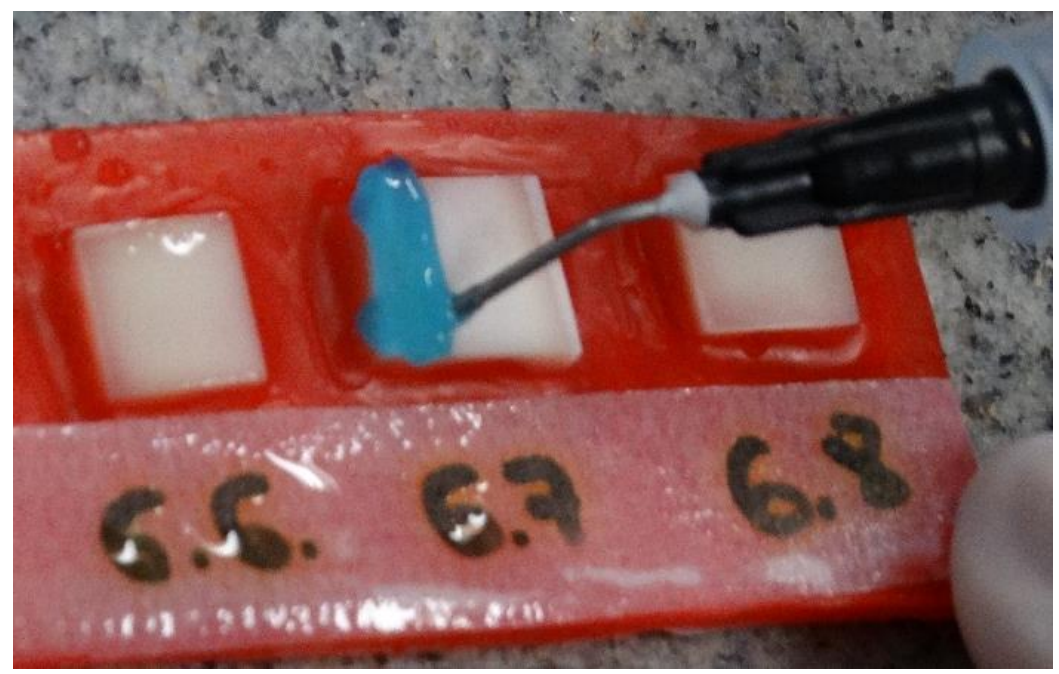

Figura 7 - Condicionamento da dentina com ácido fosfórico 37\% por 15 segundos. 


\subsection{Teste de Molhabilidade $(\theta)$}

A molhabilidade das amostras foi determinada pela medição do ângulo de contato $(\theta)$ utilizando um goniômetro (Optical Contact Angle Measurements - OCA20 DataPhysicsI Instruments $\mathrm{GmbH}$, Wurttemberg, Alemanha - Departamento de Química da FFCLRP/USP) (Figura 8). Cada corpo de prova foi posicionado sobre uma plataforma móvel com parafusos de nivelamento. Em seguida, uma gota de $10 \mu \mathrm{L}$ do adesivo (Single Bond Universal, 3M ESPE) foi dispensada sobre a superfície de dentina utilizando-se uma micropipeta (Gilson) (Figuras 9 e 10). Por meio de um sistema de iluminação, a imagem da gota sobre a superfície dentinária foi captada por um período de 2 minutos, tempo suficiente para estabilização do espalhamento da gota, observado durante experimento piloto.

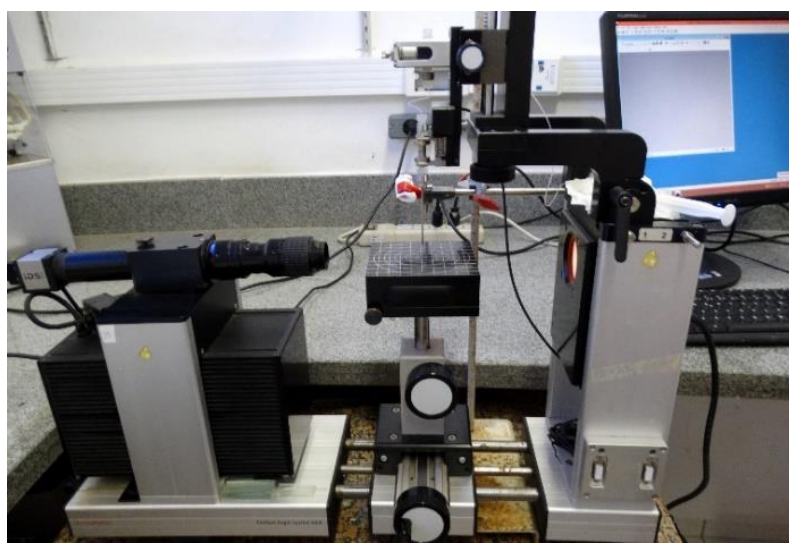

Figura 8 - Goniômetro Optical Contact Angle Measurements - OCA20.

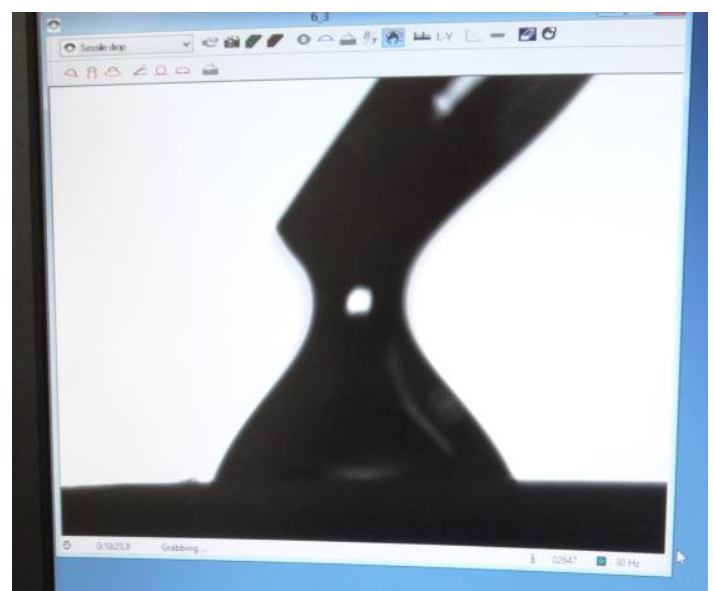

Figura 9 - Gota do adesivo sendo dispensada sobre o corpo de prova.

A imagem da gota foi processada em microcomputador e o software (SCA20Software for OCA e PCA - DataPhysics Instruments GmbH Wurttemberg - Alemanha) extraiu o seu perfil e a tangente do ângulo formado entre a gota e a superfície do lado 
esquerdo e do lado direito, tal como a média de ambos (Figura 11). Todos os procedimentos foram realizados em ambiente fechado e em temperatura ambiente controlada de $25,0 \pm 0,5^{\circ} \mathrm{C}$. As pontas da micropipeta foram trocadas a cada gota a fim de evitar a fotopolimerização do adesivo pela luz ambiente.

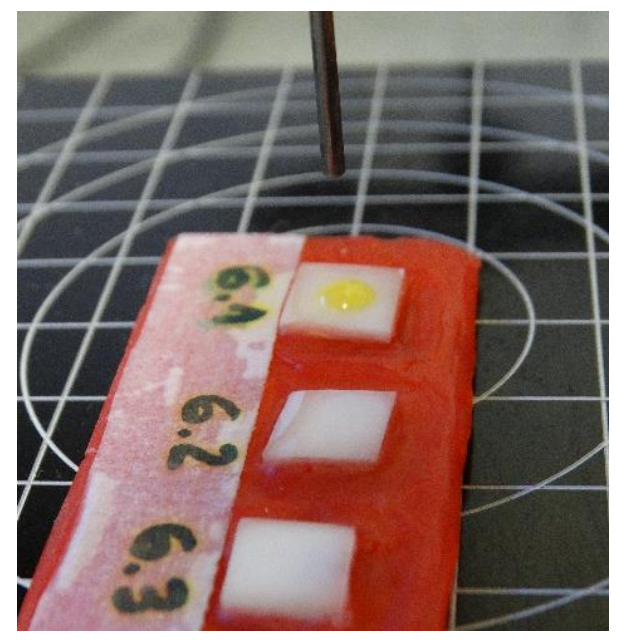

Figura 10 - gota de $10 \mu \mathrm{L}$ do adesivo (Single Bond Universal) sobre o corpo de prova centralizado sobre a mesa.

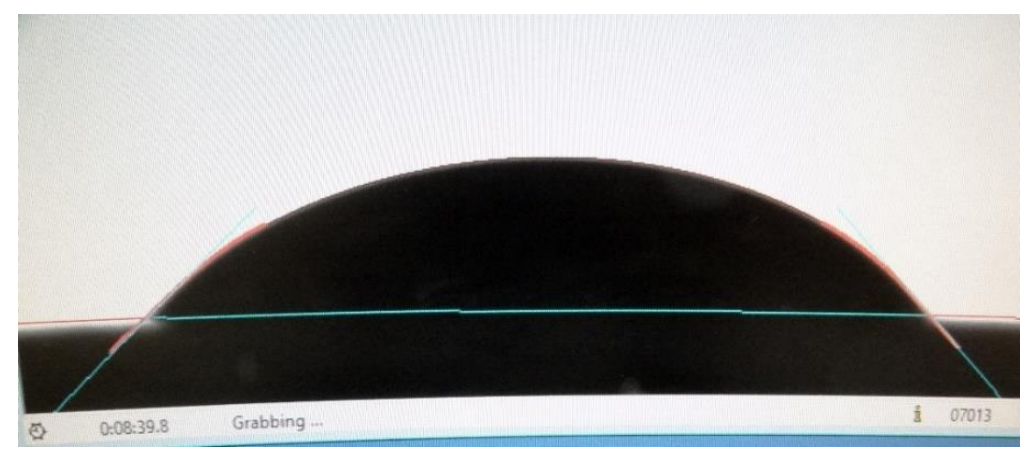

Figura 11 - Imagem da gota processada em microcomputador com seu perfil e tangentes do ângulo formado com a superfície do lado esquerdo e do lado direito extraídos pelo software. 


\subsection{Microscopia Confocal a Laser}

Doze corpos de prova foram submetidos aos quatro tratamentos dentinários após 21 dias de escovação e observados em Microscópio Confocal a Laser (OLS4000 LEXT by Olympus, Center Valley, PA, USA - Departamento de Odontologia Restauradora da FORP/USP) para análise topográfica da superfície dentinária tratada.

Os corpos de prova foram observados quanto à obliteração dos túbulos dentinários pelo dentifrício antes e após o condicionamento da dentina com ácido fosfórico 37\%, sob aumento de 100x. 
Resultades 



\section{Resultados}

Os dados de molhabilidade obtidos, representados pelas medidas dos ângulos de contato, exemplificados na Figura 12, foram agrupados em tabelas e submetidos ao teste de Normalidade Shapiro-Wilk (alfa $=5 \%$ ) e a distribuição da amostra foi normal. Assim, foi realizada a análise de Variância a dois fatores (Tabela 1) e teste complementar de Tuckey, que demonstraram a não significância para o fator Dentifrício e a Interação Dentifrício x Tempo de Escovação ( $p \geq 0.05)$, enquanto que o fator tempo de escovação, quando analisado isoladamente, teve efeito estatisticamente significante sobre a variável molhabilidade. Portanto, a hipótese nula de que os dentifrícios não alterariam a molhabilidade do substrato foi aceita, porém a hipótese nula de que com o tempo não haveria alteração significante na molhabilidade do substrato foi rejeitada.

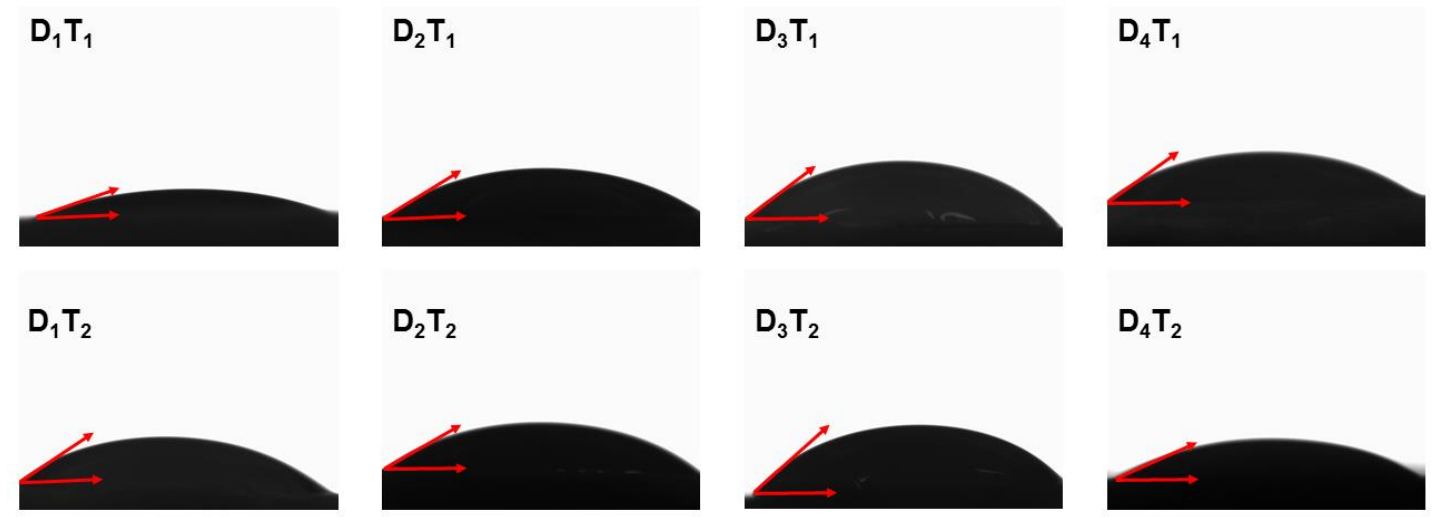

Figura 12 - Representação esquemática do ângulo de contato formado entre o substrato dentinário e uma gota do adesivo, nas diferentes condições experimentais. 
Tabela 1 - Resumo da análise de variância.

\begin{tabular}{|c|c|c|c|c|}
\hline $\mathrm{FV}$ & $\mathrm{GL}$ & $S Q$ & QM & $\mathrm{F}$ \\
\hline DENTIFRÍCIO (D) & 3 & 42.32717 & 14.10906 & $0.1818 \mathrm{~ns}$ \\
\hline TEMPO (T) & 1 & 539.73453 & 539.73453 & 6.9550 * \\
\hline Interação DxT & 3 & 132.05612 & 44.01871 & $0.5672 \mathrm{~ns}$ \\
\hline Tratamentos & 7 & 714.11781 & 102.01683 & $1.3146 \mathrm{~ns}$ \\
\hline Resíduo & 72 & 5587.47084 & 77.60376 & \\
\hline Total & 79 & 6301.58865 & & \\
\hline
\end{tabular}

\subsection{Fator Dentifrício}

A não significância estatística do fator Dentifrício, quando analisado isoladamente (Tabela 2, Gráfico 1), demonstra que a ação das diferentes condições experimentais de escovação não determinou alterações significantes na molhabilidade da dentina.

Tabela 2 - Médias de ângulo de contato $(\theta)$ do fator Dentifrício.

\begin{tabular}{c|c|c|c}
\hline \hline $\mathbf{D}_{1}$ & $\mathbf{D}_{2}$ & $\mathbf{D}_{3}$ & $\mathbf{D}_{\mathbf{4}}$ \\
\hline $29,45 \pm 9,0^{\mathrm{a}}$ & $28,73 \pm 9,1^{\mathrm{a}}$ & $30,47 \pm 8,7^{\mathrm{a}}$ & $28,66 \pm 9,5^{\mathrm{a}}$ \\
\hline
\end{tabular}

Letras iguais indicam semelhança estatística. 


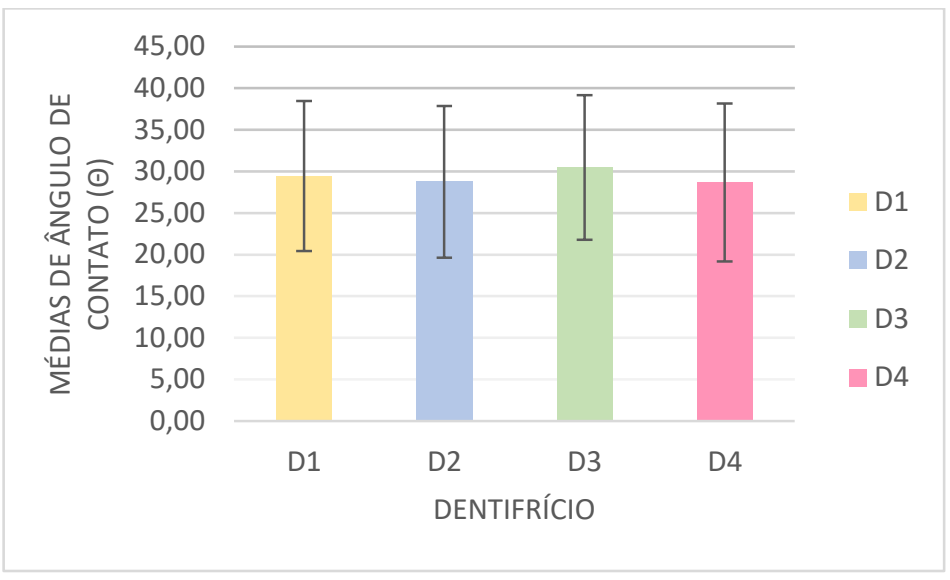

Gráfico 1 - Médias de ângulo de contato $(\theta)$ do fator Dentifrício.

\subsection{Fator Tempo de Escovação}

O fator Tempo de Escovação, isoladamente, teve efeito estatisticamente significante sobre a molhabilidade $(\theta)$ da superfície dentinária. De acordo com a Tabela 3, o Tempo de escovação $T_{1}$ (7 dias) determinou menor média de molhabilidade que $T_{2}$ (21 dias), indicando que a molhabilidade do substrato foi reduzida com o tempo (Gráfico 2).

Tabela 3 - Médias de ângulo de contato $(\theta)$ do fator Tempo de Escovação.

\begin{tabular}{c|c}
\hline \hline $\mathbf{T}_{1}$ & $\mathbf{T}_{2}$ \\
\hline $26,73 \pm 8,1^{\mathrm{b}}$ & $31,93 \pm 9,0^{\mathrm{a}}$ \\
\hline \hline
\end{tabular}

Letras diferentes indicam diferença estatística.

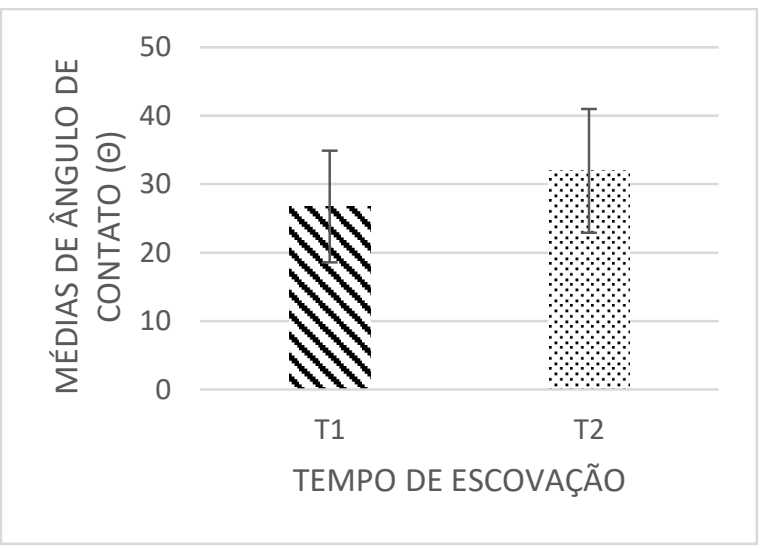

Gráfico 2 - Médias de ângulo de contato $(\theta)$ do fator Tempo de Escovação. 


\subsection{Interação Dentifrício x Tempo de Escovação}

De acordo com a análise de variância nenhum dos tratamentos teve efeito estatisticamente significante sobre a molhabilidade do substrato. As médias obtidas para cada condição experimental constam na Tabela 5 e com as quais foi construído o Gráfico 3.

Tabela 5 - Médias de ângulo de contato $(\theta)$ da interação Dentifrício x Tempo de Escovação.

\begin{tabular}{c|c|c}
\hline & $\mathbf{T}_{\mathbf{1}}$ & $\mathbf{T}_{\mathbf{2}}$ \\
\hline $\mathbf{D}_{\mathbf{1}}$ & $24,69 \pm 5,8^{\mathrm{a}}$ & $34,21 \pm 9,3^{\mathrm{a}}$ \\
\hline $\mathbf{D}_{\mathbf{2}}$ & $26,71 \pm 9,9^{\mathrm{a}}$ & $30,76 \pm 8,3^{\mathrm{a}}$ \\
\hline $\mathbf{D}_{\mathbf{3}}$ & $28,26 \pm 9,9^{\mathrm{a}}$ & $32,68 \pm 7,1^{\mathrm{a}}$ \\
\hline $\mathbf{D}_{4}$ & $27,26 \pm 7,1^{\mathrm{a}}$ & $30,06 \pm 11,6^{\mathrm{a}}$ \\
\hline \hline
\end{tabular}

Letras iguais indicam semelhança estatística.

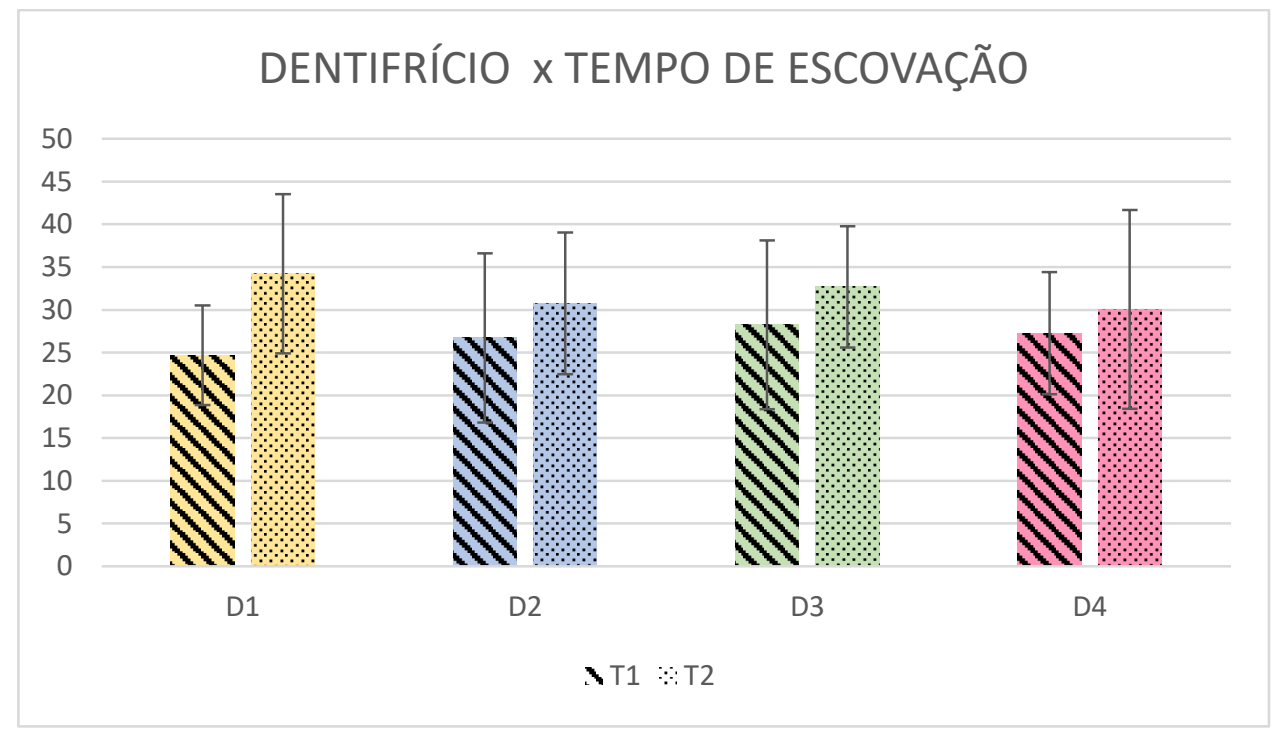

Gráfico 3 - Médias de ângulo de contato $(\theta)$ da interação Dentifrício x Tempo de Escovação. 


\subsection{Análise topográfica}

Pela análise visual das imagens obtidas na Microscopia Confocal a laser foi possível observar que $\mathrm{D}_{1}$ (dentifrício controle - Colgate ${ }^{\circledR}$ Total 12) se deposita sobre a dentina de forma sutil, obliterando poucos túbulos dentinários e nenhum após o condicionamento com ácido fosfórico (Figura 13A-B).
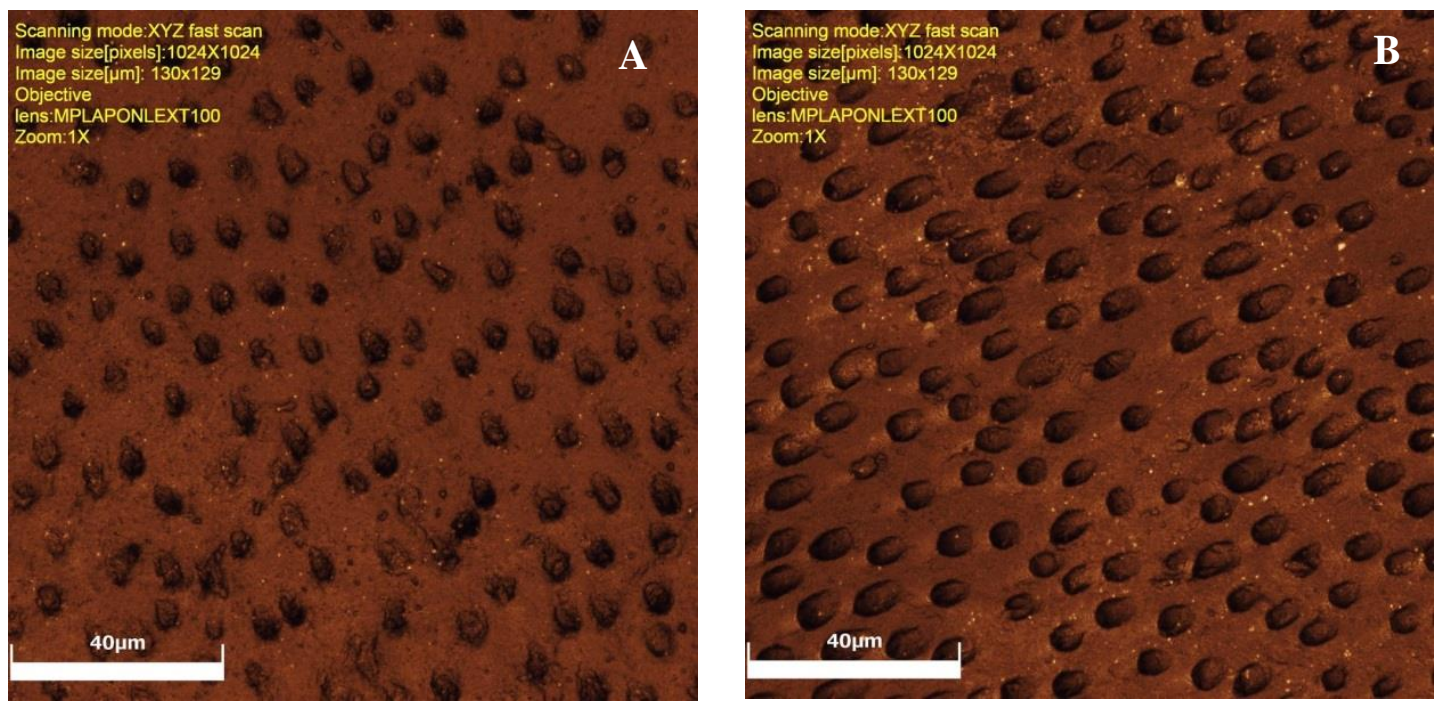

Figura 13 - (A) Fotomicrografia da dentina escovada com dentifrício controle $\left(D_{1}\right)$ antes do condicionamento com ácido fosfórico 37\%. (B) Fotomicrografia do mesmo corpo de prova após o condicionamento ácido da dentina por 15 segundos.

O dentifrício cujo agente dessensibilizante é a arginina $8 \%$ associada ao carbonato de cálcio (Pró-Argin $\AA^{\circ}$ - Colgate ${ }^{\circledR}$ Sensitive Pró-alívio ${ }^{\mathrm{TM}}$ ) obliterou a maioria dos túbulos dentinários (Figura 14A) após o tempo de escovação de 21 dias. Após o condicionamento ácido fosfórico foi possível observar que a maior parte dos túbulos antes obliterados foram reabertos (Figura 14B). 

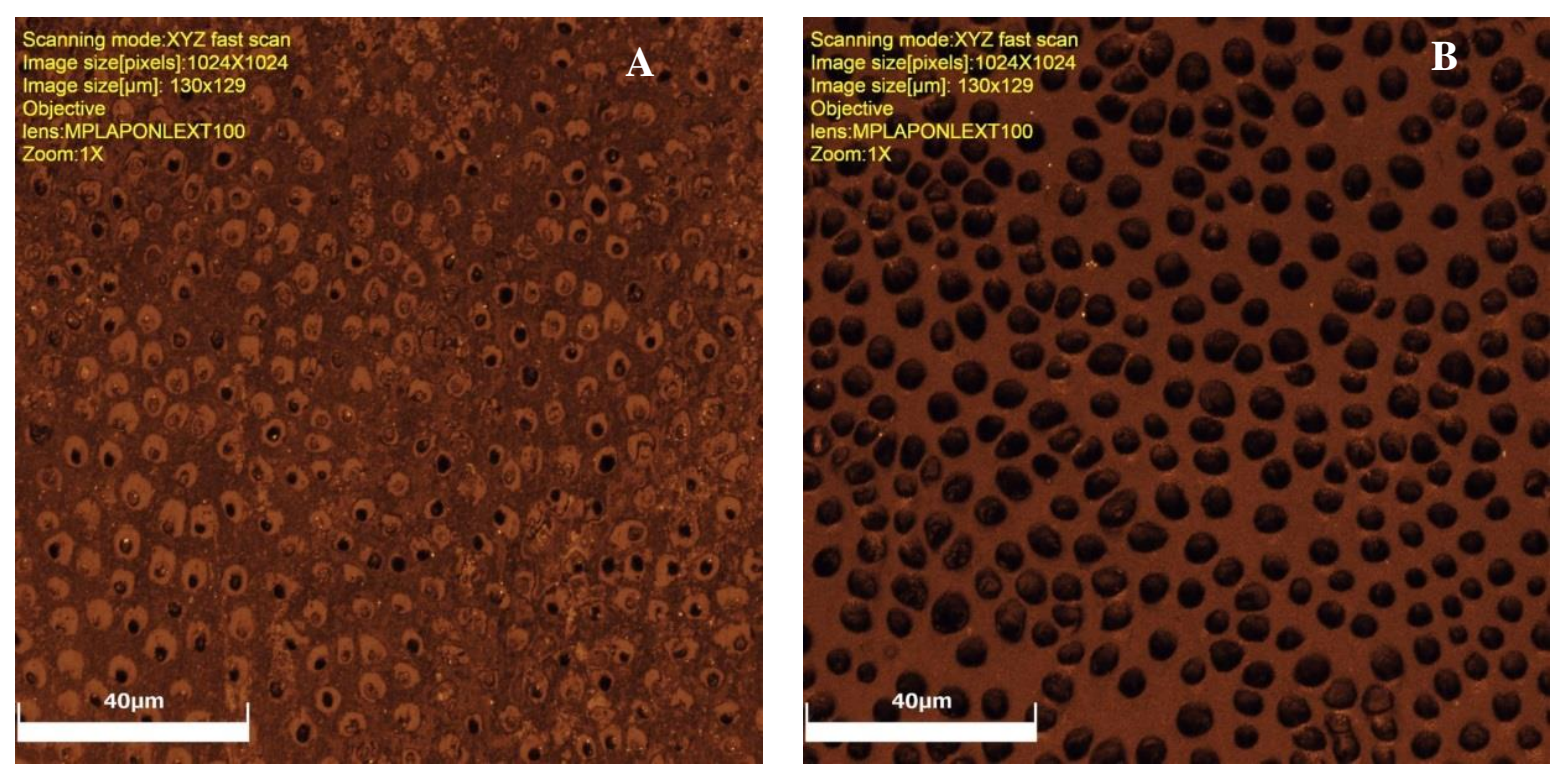

Figura 14 - (A) Fotomicrografia da dentina escovada com dentifrício contendo arginina 8\% + carbonato de cálcio $\left(D_{2}\right)$ antes do condicionamento com ácido fosfórico $37 \%$. (B) Fotomicrografia do mesmo corpo de prova após o condicionamento ácido da dentina por 15 segundos.

O dentifrício $D_{3}$ (Figura 15A-B), com fosfosilicato de cálcio e sódio (Novamin ${ }^{\circ}$ Sensodyne® Repair and Protect) e o dentifrício D4 (Figura 15C-D), com acetato de estrôncio 8\% (Sensodyne® Rápido Alívio), visualmente bloqueiam quase 100\% dos túbulos dentinários logo após os 21 dias de escovação (figura 15A e 15C). Após o condicionamento com ácido fosfórico $37 \%$ foi possível observar que, apesar da maioria dos túbulos dentinários estarem reabertos, ainda há alguns túbulos dentinários parcialmente obliterados (Figura 15B e 15D). 

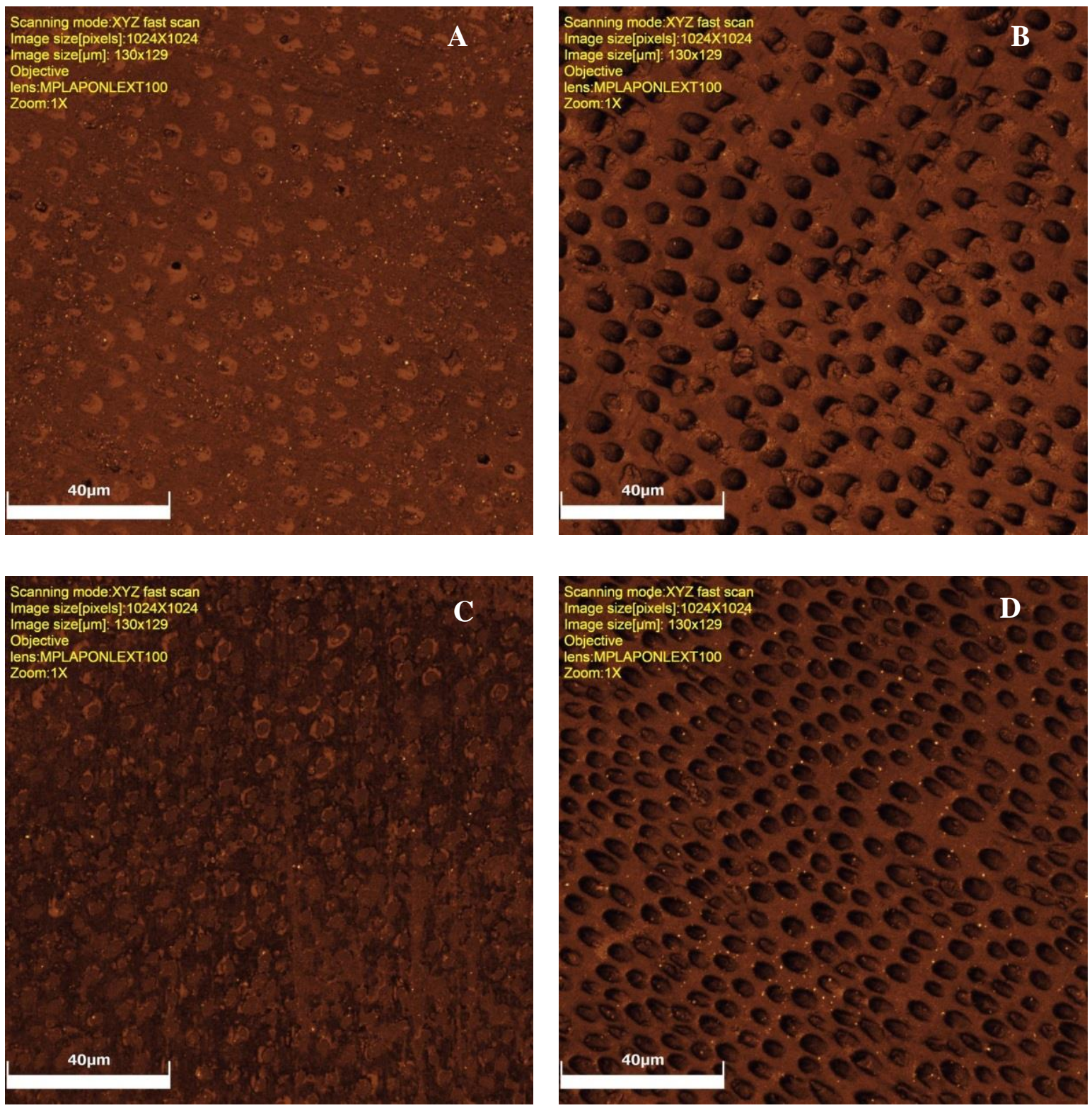

Figura 15 - (A) Fotomicrografia da dentina escovada com dentifrício contendo fosfosilicato de cálcio e sódio $\left(D_{3}\right)$ previamente ao condicionamento ácido; $(B) D_{3}$ após condicionamento ácido; (C) Fotomicrografia da dentina escovada com dentifrício contendo acetato de estrôncio $8 \%\left(D_{4}\right)$ previamente ao condicionamento ácido; (D) $D_{4}$ após condicionamento ácido. 

Discussãa 



\section{Discussão}

A principal característica da hipersensibilidade dentinária é a exposição dos túbulos dentinários a diferentes estímulos que provocam dor. A alta prevalência e o grande incômodo ao paciente que essa patologia provoca faz com que cada vez mais novos tratamentos sejam lançados no mercado com o objetivo de obliterar os túbulos dentinários expostos ou bloquear a transmissão nervosa da dor. O uso de dentifrícios com ação dessensibilizante é o tratamento mais simples e sua eficácia é comprovada em diversos trabalhos na literatura (Davies et al., 2011; Sharif et al., 2013; West et al., 2013; Pinto et al., 2014; Satyapal et al., 2014; Tunar et al., 2014; Arnold et al., 2015; Bae et al., 2015; Bal et al., 2015; Jones et al., 2015; Samuel et al., 2015; West et al., 2015; Saeki et al., 2016).

Os fabricantes dos dentifrícios dessensibilizantes recomendam seu uso diário, em substituição ao dentifrício comum e assinalam os tempos de uso mínimo para efetivar a sua ação. Segundo Douglas de Oliveira et al. (2016), a utilização destes dentifrícios por 30 dias reduz significativamente a dor quando comparado ao tempo de uso de 24 horas. Por outro lado, o uso por tempos maiores pode ser importante na alteração da morfologia dentinária, o que poderia influenciar, de certa forma, no comportamento de alguns materiais restauradores adesivos.

Nos procedimentos odontológicos, a molhabilidade da dentina é importante visto que tem relação direta com a adesão de um material restaurador ao dente, mediada por interações físicas e químicas que mantém o material e o substrato unidos, intermediada pelo uso de um adesivo (Rosales-Leal et al., 2001; Aguilar-Mendoza et al., 2008a; Farge et al., 2010). O grau de espalhamento deste adesivo sobre a dentina corresponde à medida da molhabilidade do substrato, quantificada pela medida do ângulo de contato formado entre o adesivo e a superfície, o qual depende da rugosidade superficial, da composição do substrato e sua energia de superfície (Rosales-Leal et al., 2001; de Souza et al., 2014). Por este motivo, o método de avaliação da molhabilidade utilizado nesse estudo foi pela medição do ângulo de contato formado entre a superfície dentinária e o adesivo por meio de um Goniômetro. 
A hipótese nula de que não haveria diferença na molhabilidade da dentina erodida quando submetida aos diferentes dentifrícios dessensibilizantes foi aceita. Isto pode relacionar-se com o fato de que o condicionamento ácido da dentina antes da aplicação do adesivo resultou em uma superfície semelhante entre todos os grupos, por meio da desmineralização do substrato. O condicionamento da dentina com ácido fosfórico a $37 \%$ por 15 segundos foi realizado como parte do protocolo de adesão tradicional, precedendo à aplicação do adesivo. De acordo com Aguilar-Mendoza, Rosales-Leal, Rodríguez-Valverde, González-López \& Cabrerizo-Vílchez, 2008, esse procedimento pode aumentar em até $35 \%$ a molhabilidade, visto que o mesmo aumenta a rugosidade e a energia de superfície do substrato. Para se obter alta molhabilidade, é necessário que a energia de superfície da dentina seja maior que a tensão superficial do adesivo, promovendo maior contato entre ambos (Rosales-Leal et al., 2001; Aguilar-Mendoza et al., 2008b; Ricci et al., 2011).

O fator Tempo de Escovação determinou diferença estatística significante, isto é, a molhabilidade da dentina é afetada aos 21 dias de utilização das pastas, quando comparada ao tempo de 7 dias. Como os estudos de Gjorgievska et al. (2013), Eliades et al. (2013), Pinto et al. (2014) e Olley et al. (2015) demonstraram a presença de depósitos de arginina, estrôncio, carbonato, sódio e cálcio nos tampões que obliteram os túbulos dentinários e na superfície da dentina, pode se sugerir a possibilidade de que aos 21 dias de tratamento é que acontece a quantidade de deposição de minerais suficiente para modificar a molhabilidade do substrato dentinário. No estudo de Jones et al. (2015) a utilização do dentifrício dessensibilizante com fosfosilicato de cálcio e sódio por 15 dias obliterou maior número de túbulos dentinários do que a utilização por 10 dias. Portanto, é possível que quanto maior for o tempo de escovação com dentifrícios dessensibilizantes maior seria a deposição de partículas de dentifrício sobre a superfície da dentina erodida.

Marshall et al. (2010) afirmam que a alta energia de superfície contribui para que a dentina possa ser molhada por diversas substâncias, como liquidos e sólidos macios, que possuem baixa energia de superfície. Portanto, presume-se que a aplicação sequenciada de dentifrícios com agentes dessensibilizantes e remineralizadores capazes de depositar-se sobre a superfície dentinária e no interior dos túbulos pode alterar, com o tempo, a morfologia da dentina e, como consequência, modificar a sua energia de superfície e a sua molhabilidade. 
A interação entre os dentifrícios dessensibilizantes e o tempo de escovação não teve efeito significante sobre a molhabilidade da dentina erodida $\mathrm{e}$ isto provavelmente está relacionado com a semelhança de aspecto morfológico da superfície dentinária após a escovação com os diferentes dentifrícios por meio do depósito de partículas na superfície da dentina e na embocadura dos túbulos dentinários. Os estudos de Gjorgievska et al. (2013); Bae, Kim, \& Myung (2015) e Jones et al. (2015) mostram que a deposição de íon sódio, cálcio, fosfato e de sílica pelo dentifrício composto por fosfosilicato de cálcio e sódio resulta na formação de sítios de nucleação para a precipitação de fosfato de cálcio, o qual cristaliza-se em hidroxicarbonatoapatita, inicialmente, sob a forma de partículas individuais e, com o tempo, sua degradação promove uma superfície mais homogênea sobre a dentina, e penetra nos túbulos dentinários, obliterando-os. O estrôncio substitui o cálcio na formação dos cristais de hidroxiapatita, formando o composto cálcio-estrôncio-apatita, sendo capaz de remineralizar a superfície e penetrar nos túbulos dentinários (Davies et al., 2011; Olley et al., 2012; Orsini et al., 2013; Saeki, Marshall, Gansky, Parkinson, \& Marshall, 2016). No tampão formado pelos dentifrícios compostos por arginina e carbonato de cálcio, a primeira é atraída à superfície da dentina e o carbonato de cálcio é atraído e aderido às fibras da superfície dentinária e, então, infiltra-se nos túbulos, alcalinizando o ambiente e facilitando a precipitação de íons cálcio e fosfato que vão bloquear a entrada dos túbulos dentinários (Cummins 2009; Olley et al., 2012; Gjorgievska, Nicholson, Slipper, \& Stevanovic, 2013; Mantzourani and Sharma 2013; Chen et al. 2015; Olley, Moazzez, \& Bartlett, 2015). Diante disso, os dentifrícios dessensibilizantes utilizados neste estudo, mesmo com mecanismos de ação distintos, têm como resultado a obliteração dos túbulos dentinários e a remineralização do substrato.

A semelhança entre os resultados obtidos entre dentifrícios com agentes dessensibilizantes $\left(D_{2}, D_{3}\right.$ e $\left.D_{4}\right)$ e o dentifrício controle $\left(D_{1}\right)$ pode relacionar-se com a presença de abrasivos como a sílica, que são capazes de obliterar os túbulos dentinários (Davies et al., 2011). O fluoreto, presente no dentifrício controle e no dentifrício contendo fosfosilicato de cálcio e sódio, bem como na saliva, atua como agente remineralizador através da precipitação de fosfato de cálcio e da formação de fluorhidroxiapatita na dentina e no esmalte, porém, é menos estável em soluções ácidas (Gjorgievska et al., 2013). 
A microscopia a laser confocal permitiu observar a embocadura dos túbulos dentinários e se ocorreu a obliteração dos túbulos dentinários após a aplicação do ácido fosfórico. A instabilidade dos depósitos de dentifrício nos túbulos dentinários frente ao condicionamento ácido foi observada microscopicamente nesse estudo, onde foi possível visualizar que a grande maioria dos túbulos dentinários foi reaberta. Não foram encontrados relatos na literatura que avaliam a resistência dos depósitos minerais provenientes dos dentifrícios dessensibilizantes nos túbulos dentinários frente à aplicação de ácido fosfórico 37\%, porém, diversos estudos comprovam a resistência desses depósitos à desafios com ácidos provenientes da dieta, como o suco de uva, o suco de laranja e refrigerante de cola (Petrou et al., 2009; Olley et al., 2012; Seong et al., 2013; Yamashita et al., 2013; Pinto et al., 2014; Olley et al., 2015)

Olley et al. (2012) e Seong et al. (2013) observaram que o dentifrício com acetato de estrôncio apresentou maior resistência ao desafio com bebidas ácidas quando comparado ao dentifrício com arginina e carbonato de cálcio. Os autores justificam esta ocorrência à instabilidade do tampão de arginina e carbonato de cálcio em meio ácido, visto que a arginina em pH fisiológico forma um aglomerado carregado positivamente com o carbonato de cálcio e, então, liga-se à dentina, carregada negativamente. Em condições ácidas, a carga é perdida e pode levar à dissociação do aglomerado da superfície da dentina. Já o dentifrício com acetato de estrôncio, por estar contido em uma base sílica, não seria afetado por um desafio ácido. Isso pode ter alguma relação com as imagens obtidas neste estudo, nas quais foi possível observar que o dentifrício com acetato de estrôncio apresentou maior quantidade de depósitos na sua superfície após o condicionamento com ácido fosfórico, quando comparado ao dentifrício a base de arginina $8 \%$ e carbonato de cálcio.

Segundo Pashley et al. (1993), a desmineralização da dentina pelo condicionamento com ácido fosfórico pode atingir uma profundidade entre $0,5 \mathrm{a}$ $7,5 \mu \mathrm{m}^{2}$, porém, não foram encontrados estudos recentes que avaliem a profundidade em que os depósitos minerais dos agentes dessensibilizantes podem atingir, bem como estudos que avaliem a composição mineral do substrato que recebeu 0 tratamento com os dentifrícios após a aplicação do ácido fosfórico.

Os resultados mostraram que a molhabilidade dentinária não foi influenciada pelos diferentes dentifrícios nos tempos estabelecidos neste estudo. 
O aspecto relevante deste estudo consiste na provável influência do tempo de utilização dos dentifrícios, na molhabilidade da dentina erodida, que pode favorecer o depósito dos elementos componentes de qualquer um deles, modificando as características da superfície. 

Panclusãa 



\section{Conclusão}

De acordo com a metodologia utilizada neste estudo, conclui-se que:

1. O fator Tempo de Escovação, isoladamente, determinou menor grau de molhabilidade aos 21 dias de escovação.

2. Os dentifrícios dessensibilizantes utilizados no presente estudo não interferiram na molhabilidade da dentina erodida nos tempos de escovação analisados.

Relevância Clínica: Os dentifrícios com ação dessensibilizante pela obliteração dos túbulos dentinários são amplamente utilizados por seu fácil acesso, baixo custo e eficácia, portanto, a influência destes agentes no substrato dentinário deve ser conhecida para que não haja prejuízos a possíveis procedimentos restauradores que possam ser executados após o uso prolongado destes dentifrícios. 

Referências Bibliagráficas 



\section{REFERÊNCIAS BIBLIOGRÁFICAS}

Addy M. Dentine hypersensitivity : new perspectives on an old problem. J. Contemp. Dent. Pract. 2002;6(2):107-17.

Aguilar-Mendoza JA, Rosales-Leal JI, Rodríguez-Valverde MA, González-López S, Cabrerizo-Vílchez MA. Wettability and bonding of self-etching dental adhesives. Influence of the smear layer. Dent. Mater. 2008a;24(7):994-1000.

Aguilar-Mendoza JA, Rosales-Leal JI, Rodríguez-Valverde MA, Cabrerizo-Vílchez MA. Effect of Acid Etching on Dentin Wettability and Roughness: Self-Etching Primers Versus Phosphoric Acid. J Biomed Mater Res Part B: Appl Biomater. 2008b;84B:277285.

Amaechi BT, Higham SM, Edgar WM. Factors influencing the development of dental erosion in vitro: enamel type, temperature and exposure time. J. Oral Rehabil. 1999;26(8):624-30.

Arnold WH, Prange M, Naumova EA. Effectiveness of various toothpastes on dentine tubule occlusion. J. Dent. 2015;1-10.

Bae JH, Kim YK, Myung SK. Desensitizing toothpaste versus placebo for dentin hypersensitivity: A systematic review and meta-analysis. J. Clin. Periodontol. 2015;42(2):131-41.

Bal MV, Keskiner İ, Sezer U, Açıkel C, Saygun I. Comparison of low level laser and arginine-calcium carbonate alone or combination in the treatment of dentin hypersensitivity: a randomized split-mouth clinical study. Photomed. Laser Surg. 2015;33(4):200-5.

Brännström M. The hydrodynamic theory of dentinal pain: Sensation in preparations, caries, and the dentinal crack syndrome. J. Endod. 1986;12(10):453-7.

Chabanski MB, Gillam DG, Bulman JS, Newman HN. Clinical evaluation of cervical dentine sensitivity in a population of patients referred to a specialist periodontology department: a pilot study. J. Oral Rehabil. 1997;24(9):666-72. 
Chen CL, Parolia A, Pau A, Celerino De Moraes Porto IC. Comparative evaluation of the effectiveness of desensitizing agents in dentine tubule occlusion using scanning electron microscopy. Aust. Dent. J. 2015;60(1):65-72.

Cohen A. Preliminary study of the effects of a strontium Chloride dentifrice for the control of Hypersensitive teeth. Oral Medicine. 1961;14(9):1046-1052.

Costa RSA, Rios FS, Moura MS, Jardim JJ, Maltz M, Haas AN. Prevalence and risk indicators of dentin hypersensitivity in adult and elderly populations from Porto Alegre, Brazil. J. Periodontol. 2014;85(9):1247-58.

Cummins D. Dentin hypersensitivity: From diagnosis to a breakthrough therapy for everyday sensitivity relief. J. Clin. Dent. 2009;20(1):1-9.

Davari A, Ataei E, Assarzadeh H. Dentin Hypersensitivity: Etiology, Diagnosis and Treatment; A Literature Review. J. Dent. 2013;14(3):136-45.

Davies M, Paice EM, Jones SB, Leary S, Curtis AR, West NX. Efficacy of desensitizing dentifrices to occlude dentinal tubules. Eur. J. Oral Sci. 2011;119(6):497-503.

Eick JD, Gwinnett AJ, Pashley DH, Robinson SJ. Current concepts on adhesion to dentin. Crit. Rev. Oral Biol. Med. 1997;8(3):306-35.

Eliades G, Mantzourani M, Labella R, Mutti B, Sharma D. Interactions of dentine desensitisers with human dentine: Morphology and composition. J. Dent. 2013;41(SUPPL. 4):S28-39.

Farge P, Alderete L, Ramos SMM. Dentin wetting by three adhesive systems: Influence of etching time, temperature and relative humidity. J. Dent. 2010;38(9):698706.

Gillam DG, Aris A, Bulman JS, Newman HN, Ley F. Dentine hypersensitivity in subjects recruited for clinical trials: Clinical evaluation, prevalence and intra-oral distribution. J. Oral Rehabil. 2002;29(3):226-31.

Gjorgievska ES, Nicholson JW, Slipper IJ, Stevanovic MM. Remineralization of demineralized enamel by toothpastes: a scanning electron microscopy, energy dispersive $\mathrm{x}$-ray analysis, and three-dimensional stereo-micrographic study. Microsc Microanal. 2013;19(3):587-95.

Haneet RK, Vandana LK. Prevalence of dentinal hypersensitivity and study of 
associated factors: A cross-sectional study based on the general dental population of Davangere, Karnataka, India. Int. Dent. J. 2016;66(1):49-57.

Jones SB, Parkinson CR, Jeffery P, Davies M, Macdonald EL, Seong J, et al. A randomised clinical trial investigating calcium sodium phosphosilicate as a dentine mineralising agent in the oral environment. J. Dent. 2015;43(6):757-64.

Mantzourani M, Sharma D. Dentine sensitivity: Past, present and future. J. Dent. 2013;41(SUPPL. 4):S3-17.

Markowitz K, Pashley DH. Personal Reflections on a Sensitive Subject. J Dent Res. 2007;292-5.

Marshall SJ, Bayne SC, Baier R, Tomsia AP, Marshall GW. A review of adhesion science. Dent. Mater. 2010;26(2):11-6.

Miyazaki M, Tsujimoto A, Tsubota K, Takamizawa T, Kurokawa H, Platt JA. Important compositional characteristics in the clinical use of adhesive systems. J. Oral Sci. 2014;56(1):1-9.

Naidu GM, Chaitanya Ram K, Sirisha NR, Sandhya Sree Y, Kopuri RKC, Satti NR, et al. Prevalence of dentin hypersensitivity and related factors among adult patients visiting a dental school in andhra pradesh, South India. J. Clin. Diagnostic Res. 2014;8(9):ZC48-ZC51.

Olley RC, Moazzez R, Bartlett D. Effects of dentifrices on subsurface dentin tubule occlusion: an in situ study. Int. J. Prosthodont. 2015;28(2):181-7.

Olley RC, Pilecki P, Hughes N, Jeffery P, Austin RS, Moazzez R, et al. An in situ study investigating dentine tubule occlusion of dentifrices following acid challenge. J. Dent. 2012;40(7):585-93.

Orsini G, Procaccini M, Manzoli L, Sparabombe S, Tiriduzzi P, Bambini F, et al. A 3day randomized clinical trial to investigate the desensitizing properties of three dentifrices. J. Periodontol. 2013;84(11):e65-73.

Parkinson CR, Willson RJ. A comparative in vitro study investigating the occlusion and mineralization properties of commercial dentifrices in a four-day dentin disc model, in vitro. J. Clin. Dent. 2011;22:68-73.

Pashley DH, Ciucchi B, Sano H, Horner J. Permeability of dentin to adhesive agents. 
Quintessence Int. 1993;24(9):618-31.

Petrou I, Heu R, Stranick M, Lavender S, Zaidel L, Cummins D, et al. A breakthrough therapy for dentin hypersensitivity: how dental products containing $8 \%$ arginine and calcium carbonate work to deliver effective relief of sensitive teeth. J. Clin. Diagnostic Res. 2009;20(1):23-31.

Pilo R, Harel N, Nissan J, Levartovsky S. The Retentive Strength of Cemented Zirconium Oxide Crowns after Dentin Pretreatment with Desensitizing Paste Containing 8\% Arginine and Calcium Carbonate. Int. J. Mol. Sci. 2016;17(4):426.

Pinto SCS, Bandeca MC, Pinheiro MC, Cavassim R, Tonetto MR, Borges AH, et al. Preventive effect of a high fluoride toothpaste and arginine-carbonate toothpaste on dentinal tubules exposure followed by acid challenge: a dentine permeability evaluation. BMC Res. Notes. 2014;7:385.

Rosales-Leal JI, Osorio R, Holgado-Terriza JA, Cabrerizo-Vílchez MA, Toledano M. Dentin wetting by four adhesive systems. Dent. Mater. 2001;17(6):526-32.

Ricci HA, Scheffel DLS, Baldan LG, Santos FJ, Jafeliccijr M, Hebling J. Influência da Clorexidina na Capacidade de Umectablidade da Dentina Hígida e Afetada por Cárie por um Sistema Adesivo. 2011;18(1994):119-24.

Saeki K, Marshall GW, Gansky SA, Parkinson CR, Marshall SJ. Strontium effects on root dentin tubule occlusion and nanomechanical properties. Dent. Mater. The Academy of Dental Materials; 2016;32(2):240-51.

Saikaew P, Chowdhury AFMA, Fukuyama M, Kakuda S, Carvalho RM, Sano H. The effect of dentine surface preparation and reduced application time of adhesive on bonding strength. J. Dent. 2016;47:63-70.

Samuel SR, Khatri SG, Acharya S, Patil ST. Evaluation of instant desensitization after a single topical application over 30 days: A randomized trial. Aust. Dent. J. 2015;60(3):336-42.

Satyapal T, Mali R, Mali A, Patil V. Comparative evaluation of a dentifrice containing calcium sodium phosphosilicate to a dentifrice containing potassium nitrate for dentinal hypersensitivity: A clinical study. J. Indian Soc. Periodontol. 2014;18(5):581-585.

Scatolin RS, Galo R, Corona SAM. In Situ Effect of Dentifrices Associated to CO 2 Laser in the Permeability of Eroded Root Dentin. Photomed. Laser Surg. 
2012;30(10):573-8.

Seong J, Macdonald E, Newcombe RG, Davies M, Jones SB, Johnson S, et al. In situ randomised trial to investigate the occluding properties of two desensitising toothpastes on dentine after subsequent acid challenge. Clin. Oral Investig. 2013;17(1):195-203.

Sharif MO, Iram S, Brunton PA. Effectiveness of arginine-containing toothpastes in treating dentine hypersensitivity: A systematic review. J. Dent. 2013;41(6):483-92.

Sorgini DB, da Silva-Lovato $\mathrm{CH}$, de Souza RF, Davi LR, Paranhos H de FO. Abrasiveness of conventional and specific denture-cleansing dentifrices. Braz. Dent. J. 2012;23(2):154-9.

Tsujimoto A, Barkmeier WW, Takamizawa T, Watanabe H, Johnson WW, Latta MA, et al. Influence of duration of phosphoric acid pre-etching on bond durability of universal adhesives and surface free-energy characteristics of enamel. Eur. J. Oral Sci. 2016;124(4):377-86.

Tunar OL, Gursoy H, Cakar G, Kuru B, Ipci SD, Yilmaz S. Evaluation of the effects of Er:YAG laser and desensitizing paste containing $8 \%$ arginine and calcium carbonate, and their combinations on human dentine tubules: a scanning electron microscopic analysis. Photomed. Laser Surg. 2014;32(10):540-5.

Vanuspong W, Eisenburger M, Addy M. Cervical tooth wear and sensitivity: erosion, softening and rehardening of dentine; effects of $\mathrm{pH}$, time and ultrasonication. J. Clin. Periodontol. 2002;29(4):351-7.

Wang Y, Liu S, Pei D, Du X, Ouyang X, Huang C. Effect of an $8.0 \%$ arginine and calcium carbonate in-office desensitizing paste on the microtensile bond strengh of self-etching dental adhesives to human dentin. Am. J. Dent. 2012;25(5):281-6.

Wang Z, Ma X, Jiang T, Wang Y, Feng Y, Li R. The dentin tubule occlusion effects of desensitizing agents and the stability against acids and brushing challenges. Am. J. Dent. 2015;28(3):128-32.

West N, Newcombe RG, Hughes N, Mason S, Maggio B, Sufi F, et al. A 3-day randomised clinical study investigating the efficacy of two toothpastes, designed to occlude dentine tubules, for the treatment of dentine hypersensitivity. J. Dent. 2013;41(2):187-94. 
West NX, Seong J, Davies M. Management of dentine hypersensitivity: efficacy of professionally and self-administered agents. J. Clin. Periodontol. 2015;42 Suppl $1:$ S256-302.

Yang H, Pei D, Chen Z, Lei J. Effects of the application sequence of calcium-containing desensitising pastes during etch-and-rinse adhesive restoration. J. Dent. 2014;2:1115-23.

Yamashita JM, Torres NM, Moura-Grec PG, Marsicano JA, Sales-Peres A, SalesPeres SHC. Role of arginine and fluoride in the prevention of eroded enamel: An in vitro model. Aust. Dent. J. 2013;58(4):478-82.

Zhu M, Li J, Chen B, Mei L, Yao L, Tian J, et al. The effect of calcium sodium phosphosilicate on dentin hypersensitivity: A systematic review and meta-analysis. PLoS One. 2015;10(11):1-15. 
Anexas 



\section{ANEXO A}

Tabela de dados de molhabilidade com as medidas dos ângulos de contato $(\theta)$ dos lados direito e esquerdo e suas respectivas médias para o tempo de escovação de 7 dias $\left(T_{1}\right)$.

\begin{tabular}{|c|c|c|c|c|c|c|c|c|c|c|c|c|}
\hline \multicolumn{13}{|c|}{ Dados de Molhabilidade - $T_{1}$ (7 dias) } \\
\hline & \multicolumn{3}{|c|}{ D1 } & \multicolumn{3}{|c|}{ D2 } & \multicolumn{3}{|c|}{ D3 } & \multicolumn{3}{|c|}{ D4 } \\
\hline & $\theta \mathbf{d}$ & $\theta \mathbf{e}$ & $\theta \mathrm{m}$ & $\theta \mathbf{d}$ & $\theta \mathbf{e}$ & $\theta \mathrm{m}$ & $\theta \mathbf{d}$ & $\theta \mathbf{e}$ & $\theta \mathrm{m}$ & $\theta \mathbf{d}$ & $\theta \mathbf{e}$ & $\theta \mathrm{m}$ \\
\hline C1 & 12,87 & 18,95 & 15,91 & 29,92 & 28,96 & 29,44 & 31,34 & 31,3 & 31,32 & 21,25 & 18,52 & 19,885 \\
\hline $\mathrm{C} 2$ & 27,43 & 28,76 & 28,095 & 14,21 & 17,47 & 15,84 & 26,15 & 27,13 & 26,64 & 36,91 & 38,68 & 37,795 \\
\hline C3 & 23,77 & 24,22 & 23,995 & 36,24 & 35,47 & 35,855 & 28,94 & 31,4 & 30,17 & 32,63 & 27,58 & 30,105 \\
\hline C4 & 29,04 & 27,59 & 28,315 & 25,9 & 22,21 & 24,055 & 43,62 & 45,5 & 44,56 & 24,87 & 36,26 & 30,565 \\
\hline C5 & 15,08 & 16,95 & 16,015 & 36,31 & 29,21 & 32,76 & 16,63 & 15,39 & 16,01 & 35,12 & 31,58 & 33,35 \\
\hline C6 & 18,83 & 26,7 & 22,765 & 17,24 & 16,26 & 16,75 & 30,47 & 31,82 & 31,145 & 17,25 & 15,64 & 16,445 \\
\hline C7 & 25,71 & 22,37 & 24,04 & 29,15 & 39,1 & 34,125 & 17,02 & 24,38 & 20,7 & 25,84 & 21,37 & 23,605 \\
\hline C8 & 23,05 & 24,74 & 23,895 & 16,56 & 15,92 & 16,24 & 46,06 & 40,45 & 43,255 & 21,38 & 19,77 & 20,575 \\
\hline $\mathrm{Cg}$ & 34,06 & 36 & 35,03 & 18,49 & 18,04 & 18,265 & 17,42 & 22,21 & 19,815 & 21,9 & 29 & 25,45 \\
\hline C10 & 28,42 & 29,33 & 28,875 & 35,97 & 51,59 & 43,78 & 20,41 & 17,7 & 19,055 & 35,69 & 34,14 & 34,915 \\
\hline
\end{tabular}

Tabela de dados de molhabilidade com as medidas dos ângulos de contato $(\theta)$ dos lados direito e esquerdo e suas respectivas médias para o tempo de escovação de 21 dias $\left(\mathrm{T}_{2}\right)$.

\begin{tabular}{|c|c|c|c|c|c|c|c|c|c|c|c|c|}
\hline \multicolumn{13}{|c|}{ Dados de Molhabilidade $-T_{2}$ (21 dias) } \\
\hline & \multicolumn{3}{|c|}{ D1 } & \multicolumn{3}{|c|}{ D2 } & \multicolumn{3}{|c|}{ D3 } & \multicolumn{3}{|c|}{ D4 } \\
\hline & $\theta \mathbf{d}$ & $\theta \mathbf{e}$ & $\theta \mathrm{m}$ & $\theta \mathbf{d}$ & $\theta \mathbf{e}$ & $\theta \mathrm{m}$ & $\theta d$ & $\theta e$ & $\theta \mathrm{m}$ & $\theta d$ & $\theta \mathbf{e}$ & $\theta \mathrm{m}$ \\
\hline C1 & 23,9 & 24,2 & 24,05 & 37,9 & 40,4 & 39,15 & 32,9 & 32,3 & 32,6 & 32,1 & 33,2 & 32,65 \\
\hline $\mathbf{C 2}$ & 25,3 & 27,7 & 26,5 & 49,2 & 50,3 & 49,75 & 30,5 & 28,3 & 29,4 & 40,5 & 46,7 & 43,6 \\
\hline C3 & 33,5 & 30 & 31,75 & 26,1 & 24 & 25,05 & 42,4 & 45,6 & 44 & 32,9 & 33,6 & 33,25 \\
\hline C4 & 25,7 & 30,9 & 28,3 & 34,9 & 35 & 34,95 & 33,9 & 35,8 & 34,85 & 44,4 & 35,8 & 40,1 \\
\hline C5 & 50,3 & 52,9 & 51,6 & 29,4 & 30,5 & 29,95 & 31,7 & 31,9 & 31,8 & 50,4 & 47,2 & 48,8 \\
\hline C6 & 41,4 & 38,8 & 40,1 & 23 & 25,3 & 24,15 & 35,3 & 27,5 & 31,4 & 23,5 & 22,9 & 23,2 \\
\hline C7 & 46,1 & 46,3 & 46,2 & 26,4 & 24,4 & 25,4 & 22,8 & 25,5 & 24,15 & 25 & 21,4 & 23,2 \\
\hline C8 & 36,8 & 39 & 37,9 & 27,8 & 26,9 & 27,35 & 38,8 & 47,6 & 43,2 & 26,6 & 22,9 & 24,75 \\
\hline $\mathrm{Cg}$ & 26,1 & 30,2 & 28,15 & 23,7 & 24,5 & 24,1 & 36,4 & 31,2 & 33,8 & 11,8 & 13,4 & 12,6 \\
\hline C10 & 28,9 & 26,3 & 27,6 & 27,8 & 27,8 & 27,8 & 22,7 & 20,5 & 21,6 & 20,5 & 16,4 & 18,45 \\
\hline
\end{tabular}




\section{ANEXO B}

Teste de Normalidade:

Normalidade dos dados (alfa $=5 \%$ )

Teste (Estatística) Valor p-valor Normal

$\begin{array}{llll}\text { Shapiro-Wilk (W) } & 0.97117 & 0.06744 & \text { Sim }\end{array}$ 